\title{
Application of phase change materials for thermal energy storage in concentrated solar thermal power plants: A review to recent developments
}

(1)

\section{ABSTRACT}

The objective of this paper is to review the recent technologies of Thermal Energy Storage (TES) using Phase Change Materials (PCM) for various applications, particularly Concentrated Solar Thermal Power (CSP) generation systems. Fiveissues of the technology will be discussed based on a survey to the state-of-the-art development and understandings. The first part is about various phase change materials (PCM) in thermal storage applications and recent development of PCM encapsulation technologies. The second is the current status of research and application of latent heat storage systems in CSP plants.The third is the mathematical modeling and numerical simulations to the phenomenon of latent heat thermal storage. The fourth is about the issues of integration of a PCM-based TES unit into a power generation system and the operation. The last part is a discussion about the cost issues and comparison between sensible and latent heat TES systems.The surveyed information will be very helpful to researchers and engineers in energy storage industry and particularly solar thermal power industry.

\section{KEYWORDS}

Concentrated Solar Power (CSP), Thermal Energy Storage (TES), Phase Change Material (PCM), latent heat. 


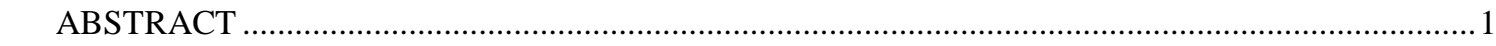

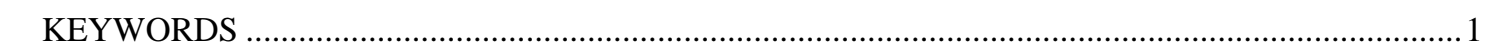

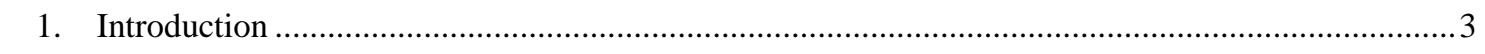

2. Various PCMs for different thermal storage applications and recent development of PCM

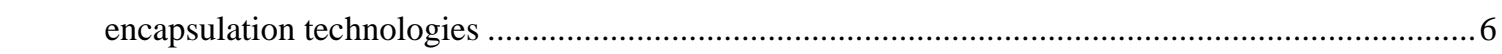

2.1. Introduction to PCMs for different thermal storage applications .................................................6

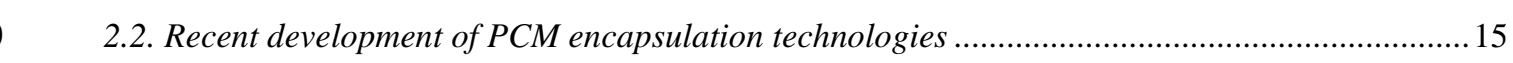

3. Current status of research and application of LHTES systems for CSP plants..................................17

3.1. Brief introduction to CSP technologies with incorporation of energy storage …...........................17

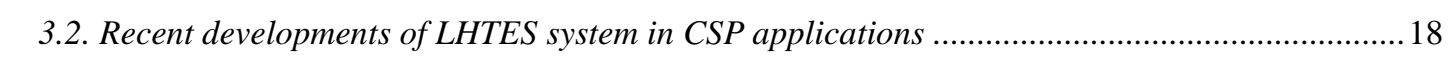

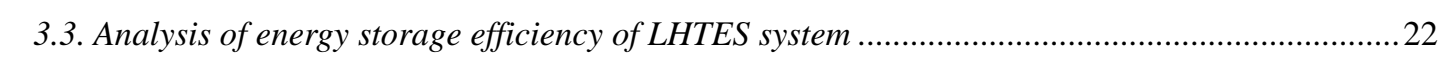

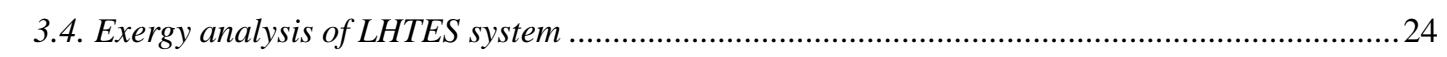

4. Mathematical modeling and numerical simulation to latent-heat thermal storage ............................27

5. Integration and seamless operation of CSP using thermocline LHTES system.................................. 37

6. Cost analysis for thermocline LHTES system …………......................................................... 41

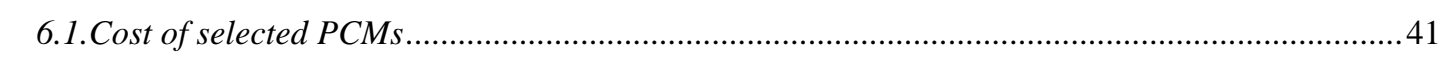

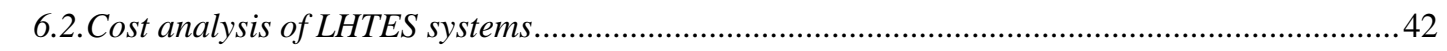

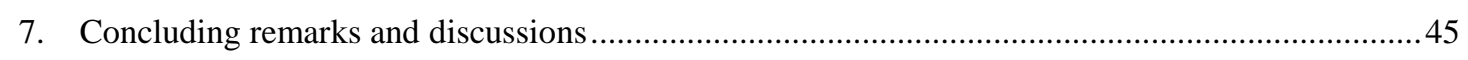

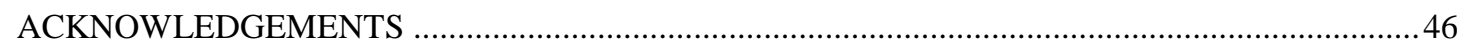

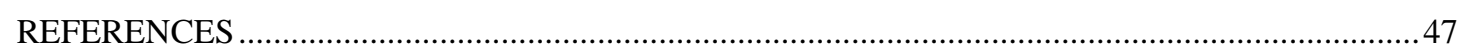




\section{Introduction}

According to the 'World Energy Outlook 2014' issued by International Energy Agency (IEA), global energy demand will increase by one third from 2011 to 2035, and energy-related $\mathrm{CO}_{2}$ emission will rise by $20 \%$, to 37.2 Gigaton if fossil fuels are used as usual [1]. To alleviate the associated environmental problems, reduction of the use of fossil fuels by developing more cost-effective renewable energy technologies becomes more and more contingent. Among various types of renewable energy sources, solar energy takes a large proportion [2].

Solar Photovoltaic (PV) power generation and Concentrated Solar Thermal Power (CSP) are the two main technologies for solar energy harvest. A CSP system may use a solar power tower, parabolic troughs, or linear Fresnel reflectors to concentrate sunlight and produce intense heat which is carried away by a heat transfer fluid (HTF) to send to the thermal power plant (or called as power block) for power generation [3]. Solar PV systems directly convert solar energy to electricity by using solar cells [4]. The energy conversion efficiency of a commercial grade PV is relatively low compared to CSP systems, although the cost of PV panels are getting more and more reduced due to the advancement of the technologies. The biggest disadvantage of PV-based power production is the inability of power dispatch due to the challenge of electrical energy storage [5]. Being able to provide electrical power at nighttime using large quantity of stored thermal energy, a CSP system is obviously more capable to dispatchpower than that of a PV-based solar power system. A CSP withthermal energy storage (TES)system becomes the first choice to provide flexibility for grid electricity supply and service at a large scale (>100MW) because of large capacity of thermal storage for power generation $[6,7]$.

Spain is currently the largest producer of CSP electricity, with 50 CSP plants and a total capacity of 2.304GWe. USA has 19 CSP plants in operation with a total installed capacity of 1.640GWeup to July 2015 [8].Countries like Algeria, Iran, Egypt, and Morocco have commercial power plants with CSPintegrated with natural gas combined cycles, also called as integrated solar combined cycle (ISCC).Other countries having good solar resources like United Arab Emirates, Australia, China, India, Iran,Israel, Italy, Jordan, Mexico, and South Africa also have CSP programs and commercial ordemonstration projects at different stages of construction and/or operation[8,9,10]. Most recently, a number of different types of CSP plants are under construction which will make a total of more than 
2.42 GW in the USA [8].The International Energy Agency (IEA) estimates that, globally, a CSP capacity may grow to $147 \mathrm{GW}$ in 2020 and reach $1,089 \mathrm{GW}$ by 2050 [11].

A TES system is critically needed for CSP tosmooth out the short-term transients and to extend the daytime operation to nighttime [12]. Also, of various energy storage technologies, a TES has many advantages, such as lower capital costs and high round-trip efficiency, compared to mechanical or chemical energy storage technologies.The TES system incorporated into the Solar Two project in Daggett, California,has a reported round-trip efficiency greater than 97\% [13-15].

A TES system may directly store hot HTF and pump it out at the same temperature for energy discharge, which offers the highest energy and exergy efficiencies. Since the cost of most HTFs is high, most TES systems use a cheap thermal storage medium that needs heat transfer between the storage medium and HTF. This type of TES systems must have three components, the thermal storage medium, the HTF, and the containment system. The containment system holds the storage medium and also facilitates the heat exchange between the storage medium and HTF for energy charge and discharge, and it requires a good thermal insulation from atmosphere. The use of the HTF is to supply and extract heat to/from the storage medium. Fluids serving as HTFs in commercial CSP plants include air, water/steam, mineral/synthetic oils, and inorganicmolten salts $[16,17]$. Desirable characteristics for HTFs should include low freezing point, good thermal stabilityat wide range of temperatures, low viscosity,high heat capacity, as well as acceptably low corrosion rate to metal alloys of containers and pipes holding the HTF. Low cost of HTFs is another critical criterion for industrial application $[18,19]$. For operating temperatures up to $550{ }^{\circ} \mathrm{C}$, sodium and potassium eutectic nitrate salts are currently used as HTFs.These salts are also used as thermal storage media for solar trough CSP system where expensive synthetic oil is used as HTF. Other than the limitation of the working temperature, the shortage of market supply of nitrate saltsworldwide is another issue,for example,30 times of the current mining production of nitric salts from the largest mines in Chile and Peru is required to meet the need of CSP installation as targeted by IEA for 2050 [20]. To address these issues, alternative HTFs and thermal storage media made from inexpensive and abundant materials are intensively investigated. For example, researchers in an ongoing Multi-University Research and Investigation effort funded by the U.S. Department of Energy's SunShot program use chloride salts eutectic mixture ( $\left.\mathrm{NaCl}-\mathrm{KCl}-\mathrm{ZnCl}_{2}\right)$ as a potential HTF for future CSP applications [21]. 
The storage media's sensible heat, latent heat, or combination of both, or in the form of reversible chemical reactions [22] are all possible to be utilized for thermal storage.Reference [23] presented a classification of energy storage materials. In the current CSP industry, thermal-chemical energy storage has not yet been used due to both technical and economic challenges. Mostof the studies conducted on storage materials have concentratedon sensible and latent heat storage. Studies conducted tocompare latent heat (from phase change materials-PCMs) and sensible heat thermal storage have shown thata significant reduction in storage volume can be achieved usingPCMs. Studies reported by Morrison and Abdel-Khalik [24] and Ghoneim [25] show that tostore the same amount of energy from a unit area of collector, rocks(sensible heat storage) require more than seven timesthe storage mass of Paraffin 116 Wax (P116-Wax), or five times thestorage mass of medicinal paraffin,or more than eight times thestorage mass of $\mathrm{Na}_{2} \mathrm{SO}_{4} \cdot 10 \mathrm{H}_{2} \mathrm{O}$.

Latent heat thermal energy storage (LHTES) system using PCMs is a process near isothermal that can provide significantly larger storage capacity compared to sensible heat thermal energy storage (SHTES)at the same temperature range. Isothermal storage is an important characteristic because the variation of fluid temperatures of solar field inlet and exit are constrained by the solar field equipment and also the thermal power Rankine cycles [26]. As the storage capacity of a LHTES system is governed largely by the phase change latent heatwhich is typically several ten times bigger than the sensible heat,it is possible to have smallerand lower cost thermal storage system.

To date, synthetic oils and molten salts are the most widely used sensible heat storage materials in commercialized CSP systems. LHTESsystem using PCMs for CSP plants is still under active research and development. In the present review, discussions will focus on LHTES systems.

To better understand the state-of-the-art technology of LHTES systems in CSP plants, this paper presents surveys and discussionson fivesubjects: 1)various PCMsfor different thermal storage applications; 2) current status of research and application of LHTES system in CSP plant;3) mathematical modeling and numerical simulation to LHTES system;4)integration and seamless operation of CSP using thermocline LHTES system; and 5) cost analysis of thermocline LHTES system. 
2. Various PCMs for different thermal storage applications and recent development of PCM encapsulation technologies

\subsection{Introduction to PCMs for different thermal storage applications}

A number of studies have been reported [27-30] on using different types of PCMs forLHTES. Those PCMsgenerally known for thermal storage applicationinclude organic compounds, inorganic salts and their eutectics, as categorized in Fig. 1. Organic compounds used for PCM include paraffin waxes, esters, acids and alcohols;inorganic materials include salt hydrates, eutectics of inorganic salts, and metals and their eutectics $[28,29]$. Those PCMs from organic compounds generally have low melting points and can only be used for room-heating thermal storage. For high temperature thermal storage, molten salts have been widely considered by researchers[31]. Nevertheless, since molten metals and alloys are considered as HTFs in nuclear power plants [32], they are also viewed aspossibleHTFs as well as PCMsfor thermal energy storagein CSP systems [27,33,34].

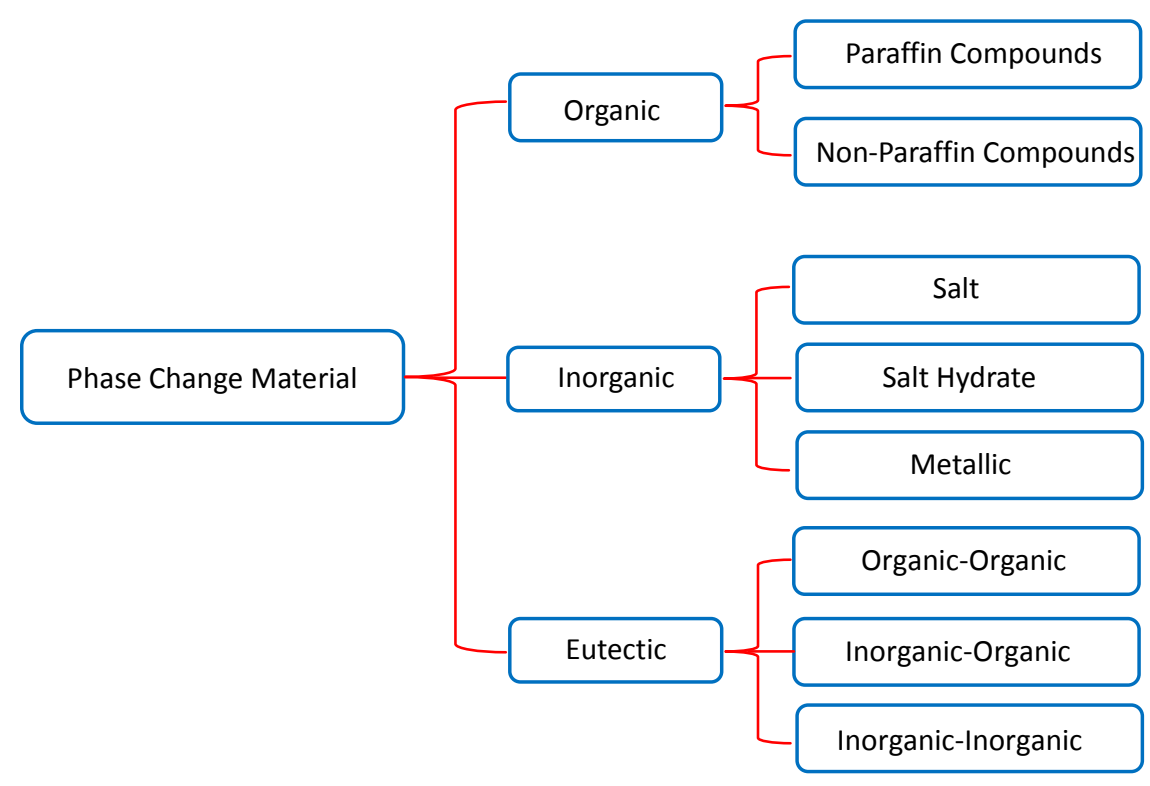

Fig.1 Classification of PCMs. [35]

From the working temperature point of view, Hoshi et al. [36] categorized those materials with melting points below $220{ }^{\circ} \mathrm{C}$ as 'low' temperature materials, melting temperatures up to $420{ }^{\circ} \mathrm{C}$ as 'medium' temperature materials, and melting point greater than $420^{\circ} \mathrm{C}$ as 'high' temperature materials suitable toCSP thermal storage.They collected the latent-heatenergy storage capacity of PCMs for 
1 various materials with melting points in the range from $300 \mathrm{~K}$ to $1200 \mathrm{~K}$ as given in Fig. 2. Specifically

2 for inorganic materials such as fluoride salts, chloride salts, carbonate salts, sulfate salts, bromide salts,

3 nitrate salts, and three eutectic salts.Fig. 3 showed the latent-heatenergy storage capacity with melting

4 point ranging from $500 \mathrm{~K}$ to $1300 \mathrm{~K}$. It is seen that the melting point of single material tends to

5 increase in the order of nitrates, chlorides, carbonates, and fluorides.

6

7

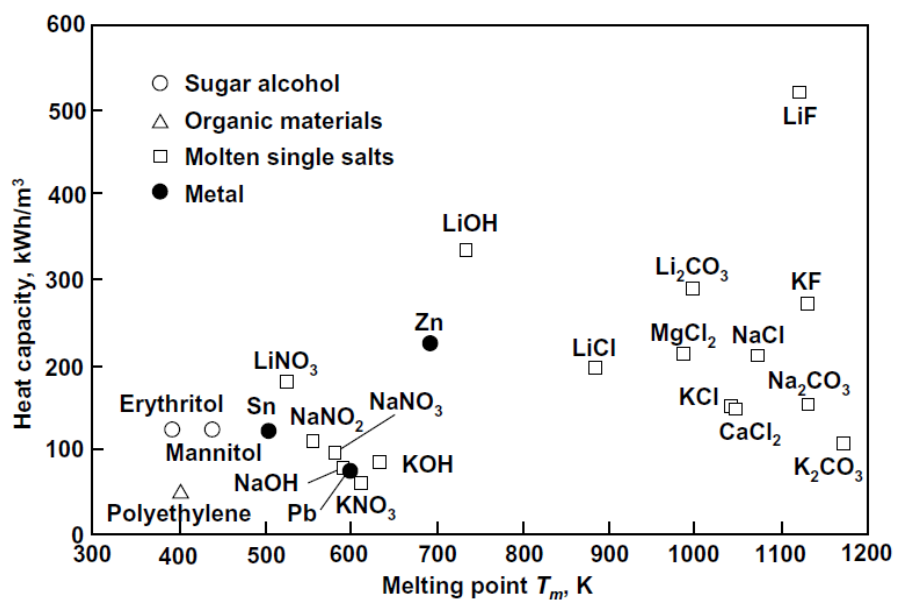

Fig.2Latent-heat-based heat storage capacity of various PCMs.[36]

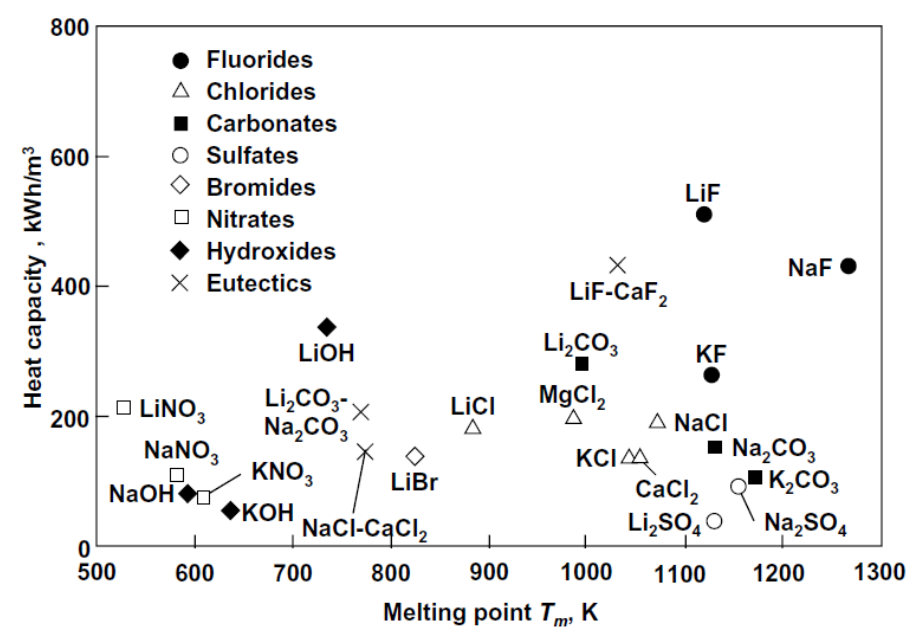

Fig.3Latent-heat-based heat storage capacity of various molten salts.[36]

The productof density and the latent heat of PCM is the energy storage capacity during the phase transition process. Some detailed data of the surveyed PCMs are given in Tables 1 to 3. Table 1 shows that $\mathrm{LiCl}-\mathrm{LiOH}$ (wt.37\%-wt.67\%)has the highest energy density during the phase transition among these 
1 seven different types of PCMs [37,38]. In Table 2, the melting temperatures of the PCMs range from

$2220^{\circ} \mathrm{C}$ to $400{ }^{\circ} \mathrm{C}$, which perfectly matches the operating temperature range of Rankine cycle. It is

3 obvious that $\mathrm{NaNO}_{3}, \mathrm{NaOH}, \mathrm{KNO}_{3}, \mathrm{NaCl}-\mathrm{KCl}$ (58:42 wt.), and $\mathrm{KOH}$ are all good candidates for

4 LHTES system. Table 3 demonstrates some PCMs potentially for high temperature applications, as

5 needed for higher thermal efficiency in a CSP system [39]. As observed in Table 3, NaF- $\mathrm{MgF}_{2}(75: 25$

6 wt.\%) with melting temperature at $650{ }^{\circ} \mathrm{C}$ is a good candidate for high temperature LHTES application.

7

8 Table IInorganic PCMs with melting temperature between $100^{\circ} \mathrm{C}$ and $280^{\circ} \mathrm{C}$

\begin{tabular}{|c|c|c|c|c|c|}
\hline Compound (wt. \%) & $\begin{array}{c}\text { Melting point } \\
\left({ }^{\circ} \mathrm{C}\right)\end{array}$ & $\begin{array}{c}\text { Latent heat } \\
(\mathrm{KJ} / \mathrm{kg})\end{array}$ & $\begin{array}{c}\text { Density } \\
\left(\mathrm{kg} / \mathrm{m}^{3}\right)\end{array}$ & $\begin{array}{c}\text { Energy density } \\
\left(\mathbf{K J} / \mathbf{m}^{\mathbf{3}}\right)\end{array}$ & $\begin{array}{c}\text { Thermal conductivity } \\
(\mathrm{W} / \mathrm{m} \cdot \mathrm{K})\end{array}$ \\
\hline $\begin{array}{c}\mathrm{MgCl}_{2} \cdot 6 \mathrm{H}_{2} \mathrm{O} \\
{[37-40]}\end{array}$ & 117 & 168.6 & $\begin{array}{c}\left.1450 \text { (liquid, } 120{ }^{\circ} \mathrm{C}\right) \\
1569\left(\mathrm{solid}, 20{ }^{\circ} \mathrm{C}\right)\end{array}$ & $\begin{array}{c}\left.\mathbf{2 4 4 4 7 0} \text { (liquid,120 }{ }^{\circ} \mathbf{C}\right) \\
\left.\mathbf{2 6 4 5 3 3} \text { (solid, 20 }{ }^{\circ} \mathrm{C}\right)\end{array}$ & $\begin{array}{c}0.570\left(\text { liquid, } 120{ }^{\circ} \mathrm{C}\right) \\
0.694\left(\mathrm{solid}, 90{ }^{\circ} \mathrm{C}\right)\end{array}$ \\
\hline $\begin{array}{c}\mathrm{NaNO}_{3}-\mathrm{KNO}_{3},(50: 50) \\
{[40,41]}\end{array}$ & 220 & 100.7 & 1920 & $\mathbf{1 9 3 3 4 4}$ & 0.56 \\
\hline $\begin{array}{c}\mathrm{KCl}-\mathrm{ZnCl},(68.1: 31.9) \\
{[40-42]}\end{array}$ & 235 & 198 & 2480 & $\mathbf{4 9 1 0 4 0}$ & 0.8 \\
\hline $\begin{array}{c}\mathrm{LiCl}-\mathrm{LiOH},(37: 67) \\
{[43,44]}\end{array}$ & 262 & 485 & 1550 & $\mathbf{7 5 1 7 5 0}$ & 1.10 \\
\hline
\end{tabular}

9

10 Table 2 Inorganic PCMs with melting temperature between $280^{\circ} \mathrm{C}$ and $400{ }^{\circ} \mathrm{C}$

\begin{tabular}{|c|c|c|c|c|c|}
\hline Compound (wt. \%) & Melting point $\left({ }^{\circ} \mathrm{C}\right)$ & $\begin{array}{c}\text { Latent heat } \\
(\mathrm{KJ} / \mathrm{kg})\end{array}$ & $\begin{array}{c}\text { Density } \\
\left(\mathrm{kg} / \mathrm{m}^{3}\right)\end{array}$ & $\begin{array}{c}\text { Energy density } \\
\left(\mathbf{K J} / \mathbf{m}^{\mathbf{3}}\right)\end{array}$ & $\begin{array}{c}\text { Thermal conductivity } \\
(\mathrm{W} / \mathrm{m} \cdot \mathrm{K})\end{array}$ \\
\hline $\mathrm{ZnCl}_{2}[40,41]$ & 280 & 75 & 2907 & $\mathbf{2 1 8 0 2 5}$ & 0.5 \\
\hline $\mathrm{NaNO}_{3}[40,41]$ & 308 & 199 & 2257 & $\mathbf{4 4 9 1 4 3}$ & 0.5 \\
\hline $\mathrm{NaOH}_{4}[40,41]$ & 318 & 165 & 2100 & $\mathbf{3 4 6 5 0 0}$ & 0.92 \\
\hline $\mathrm{KNO}_{3}[40,41]$ & 336 & 116 & 2110 & $\mathbf{2 4 4 7 6 0}$ & 0.5 \\
\hline $\mathrm{NaCl}-\mathrm{KCl},(58: 42)[40,41]$ & 360 & 119 & 2084.4 & $\mathbf{2 4 8 0 4 4}$ & 0.48 \\
\hline $\mathrm{KOH}[40,41]$ & 380 & 149.7 & 2044 & $\mathbf{3 0 5 9 8 7}$ & 0.5 \\
\hline
\end{tabular}

11

12 Table 3 Inorganic PCMs with melting temperature above $400^{\circ} \mathrm{C}$

\begin{tabular}{|c|c|c|c|c|c|}
\hline Compound (wt. \%) & MeltingPoint $\left({ }^{\circ} \mathrm{C}\right)$ & $\begin{array}{c}\text { Latent Heat } \\
(\mathrm{KJ} / \mathrm{kg})\end{array}$ & $\begin{array}{c}\text { Density } \\
\left(\mathrm{kg} / \mathrm{m}^{3}\right)\end{array}$ & $\begin{array}{c}\text { Energy Density } \\
\left(\mathbf{K J} / \mathbf{m}^{3}\right)\end{array}$ & $\begin{array}{c}\text { Thermal } \\
\text { Conductivity } \\
(\mathrm{W} / \mathrm{m} \cdot \mathrm{K})\end{array}$ \\
\hline $\begin{array}{c}\mathrm{MgCl}_{2}-\mathrm{NaCl},(38.5: 61.5) \\
{[45-47]}\end{array}$ & 435 & 351 & 2480 & $\mathbf{8 7 0 4 8 0}$ & N/A \\
\hline $\begin{array}{c}\mathrm{Na}_{2} \mathrm{CO}_{3}-\mathrm{Li}_{2} \mathrm{CO}_{3},(56: 44) \\
{[45-47]}\end{array}$ & 496 & 370 & 2320 & $\mathbf{8 5 8 4 0 0}$ & 2.09 \\
\hline
\end{tabular}




\begin{tabular}{|c|c|c|c|c|c|}
\hline $\begin{array}{c}\mathrm{NaF}-\mathrm{MgF}_{2},(75: 25) \\
{[47,48]}\end{array}$ & 650 & 860 & 2820 & $\mathbf{2 4 2 5 2 0 0}$ & 1.15 \\
\hline $\mathrm{MgCl}_{2}[41]$ & 714 & 452 & 2140 & $\mathbf{9 6 7 2 8 0}$ & N/A \\
\hline $\begin{array}{c}\mathrm{LiF}-\mathrm{CaF}_{2},(80.5: 19.5) \\
{[47,49]}\end{array}$ & 767 & 816 & 2390 & $\mathbf{1 9 5 0 2 4 0}$ & $\begin{array}{c}1.70 \text { (liquid) } \\
3.8 \text { (solid) }\end{array}$ \\
\hline $\mathrm{NaCl}[47,50]$ & 800 & 492 & 2160 & $\mathbf{1 0 6 2 7 2 0}$ & 5.0 \\
\hline $\mathrm{Na}_{2} \mathrm{CO}_{3}[47,50]$ & 854 & 275.7 & 2533 & $\mathbf{6 9 8 3 4 8}$ & 2.0 \\
\hline $\mathrm{K}_{2} \mathrm{CO}_{3}[47,50]$ & 897 & 235.8 & 2290 & $\mathbf{5 3 9 9 8 2}$ & 2.0 \\
\hline
\end{tabular}

1

2 Other than melting temperature and energy density, chemical stability, corrosion to 3 containers or capsule shells, and price are also important criteria determining the candidacy of a 4 salt for practical application.Zalba et al. [41] summarized the advantages and disadvantages of 5 organic and inorganic PCMs, and theyconcluded that inorganic PCMs have greater latent heat, but 6 with worse corrosion resistance and weaker thermal stability. Organic PCMs have very low 7 corrosion and much better thermal/chemical stability, but with a much lower latent heat and 8 thermal conductivity.Table 4 summarizes the requirement for PCMs as thermal storage materials.

9

Table 4 Requirement for PCMs as energy storage materials. [41]

\begin{tabular}{|c|c|c|c|}
\hline Thermal properties & Physical properties & Chemical properties & Economic properties \\
\hline $\begin{array}{l}\text { 1. Phase change temperature } \\
\text { fitto application }\end{array}$ & 1. Low density variation & 1. Stability & 1. Cheap and abundant \\
\hline $\begin{array}{l}\text { 2. High change of } \\
\text { enthalpy,melting point is near } \\
\text { thetemperature of use. }\end{array}$ & 2. High density & 2. No phase separation & \\
\hline $\begin{array}{l}\text { 3. High thermal conductivity } \\
\text { inboth liquid and solid } \\
\text { phases. }\end{array}$ & 3. Small or no subcooling & $\begin{array}{l}\text { 3. Compatibility with } \\
\text { containermaterials }\end{array}$ & \\
\hline & & $\begin{array}{l}\text { 4. Non-toxic, } \\
\text { non-flammable,non-polluting }\end{array}$ & \\
\hline
\end{tabular}

12 It is important to note that the candidate PCMs should melt congruently and have 13 insignificant subcooling; otherwise, the storage capacity of the system will be reduced.Through 14 experimental investigations, Liu et al. [51] found that for PCMs made from carbonate salts, the 15 freezing temperatures are usually lower than the melting temperatures, which indicates that those PCMs have higher degrees of subcooling. Compared to carbonate salts, chloride candidates $\mathrm{CH} 1$ 
$\left(52 \mathrm{MgCl}_{2}-48 \mathrm{NaCl}\right.$, wt. \%) and $\mathrm{CH} 2\left(64 \mathrm{MgCl}_{2}-36 \mathrm{KCl}\right.$, wt. \%) have much smaller degrees of subcooling. Subcooling is undesirable because it reduces the usability of PCMs and can also completely prevent heat recovery if it is too severe [52].

In most of TES applications, PCMsare normally encapsulated, the compatibility of PCM and capsule material is the first requirement. Misra and Whittenberger [53] did a pioneer work to studythe compatibility of some fluorides with 30 kinds of constructional alloys. Two eutectic salts, 80.5LiF-19.5CaF 2 wt. \% with melting point of $769^{\circ} \mathrm{C}$ and $37 \mathrm{NaF}^{2} 27 \mathrm{CaF}_{2}-36 \mathrm{MgF}_{2}$ wt. $\%$ with melting point of $905^{\circ} \mathrm{C}$,were studied at $25^{\circ} \mathrm{C}$ above their melting point. The salts and metal material were placed eitherin sealed quartz tube or in an open crucible of alumina in argon environment for 500 hours. They found that the depth of corrosionfor Hastelloy B and N was 15-30 $\mu \mathrm{m}$, and forsteel RA-330 the maximumcorrosion depth was $280 \mu \mathrm{m}$.

Recently, Gomez et al. from NREL [54] studied the corrosion of SS316 in three eutectic molten saltsat around $500 \quad{ }^{\circ} \mathrm{C}$. These salts are $80.69 \mathrm{KNO}_{3}-11.87 \mathrm{KBr}-7.44 \mathrm{KCl}$ wt.\%, $60.00 \mathrm{MgCl}_{2}-20.40 \mathrm{KCl}-19.60 \mathrm{NaCl}$ wt. $\%$, and $34.81 \mathrm{NaCl}-32.29 \mathrm{KCl}-32.90 \mathrm{LiCl}$ wt. $\%$. While the first salt has very low corrosion to SS316, the other two salts can have significant corrosion to SS316. Qiu and Galbraith [55] investigated the chemical corrosions of a $\mathrm{NaCl} / \mathrm{NaF}$ eutectic salt to the containers/capsule made from SS316 and Inconel 625 sample coupon at temperatures ranging from ambient temperature to $750{ }^{\circ} \mathrm{C}$. The containers were filled with salt in a controlled-atmosphere glove boxand were then sealed by electron-beam welding. After keeping at $750{ }^{\circ} \mathrm{C}$ for 2500 hours, the containers were cut open so that the materials of containers and coupon samples were analyzed and evaluated. At 100 hours corrosion test, both SS316 and Inconel 625 exhibited a very small amount of corrosion. The stainless steel container suffered a shallow inter-granular grain boundary attack, on the order of 1-2 $\mu \mathrm{m}$ in depth. The Inconel 625 surface formed an oxide complex, which was resistant to dissolution into the molten salt. At 2500 hours of corrosion, the surface morphology for both materials was largely unchanged, with the corrosion process having switched from an initial localized pattern, to a more uniform pattern. The corrosion depth measured at 2500 hours remained near 1-2 $\mu \mathrm{m}$, suggesting that the corrosion rate decelerated. Both materials showed promise for compatibility with the chosen salts.

A careful survey was conducted about high temperature PCM encapsulation technology 
1

2

4

5

Table 5Commercial available PCMs from PCM Products Ltd.[56]

\begin{tabular}{|c|c|c|c|c|}
\hline PCM & $\begin{array}{c}\text { Melting point } \\
\left({ }^{\circ} \mathbf{C}\right)\end{array}$ & $\begin{array}{c}\text { Latent heat } \\
(\mathbf{k J} / \mathbf{k g})\end{array}$ & $\begin{array}{c}\text { Density } \\
\left(\mathbf{k g} / \mathbf{m}^{\mathbf{3}}\right)\end{array}$ & Product materials \\
\hline H300 & 302 & 130 & 1,900 & PlusICE PCM High temperature range \\
\hline H395 & 395 & 215 & 2,330 & PlusICE PCM High temperature range \\
\hline H430 & 430 & 125 & 2,160 & PlusICE PCM High temperature range \\
\hline H500 & 500 & 300 & 2,220 & PlusICE PCM High temperature range \\
\hline H535 & 535 & 130 & 2,320 & PlusICE PCM High temperature range \\
\hline H610 & 610 & 410 & 2,070 & PlusICE PCM High temperature range \\
\hline H650 & 652 & 300 & 2,450 & PlusICE PCM High temperature range \\
\hline H700 & 699 & 250 & 2,410 & PlusICE PCM High temperature range \\
\hline H755 & 755 & 466 & 2,160 & PlusICE PCM High temperature range \\
\hline H885 & 885 & 236 & 2,290 & PlusICE PCM High temperature range \\
\hline
\end{tabular}

6

7 HTF can flow around.

13 14 15 andindustrial suppliers. Only one data source [56] shows encapsulated PCM with phase change temperature upto $885{ }^{\circ} \mathrm{C}$. Table 5 shows some collectedthermo-physical properties of the series of encapsulated PCM products. (1)

It must have effective heat exchange between PCM and heat transfer fluid in order to have high round-trip energy storage efficiency. Therefore, PCMs aretypically contained such that either large heat transfer surface area or high convective heat transfer coefficient between PCM package and HTF is possible. Fig. 4(a) shows ashell PCM container [57] with HTF in a tube, Fig. 4(b) a cylindrical PCM container[58,59] with HTF flowing around,and Fig. 4(c)a rectangular plate PCM container [60,61]that
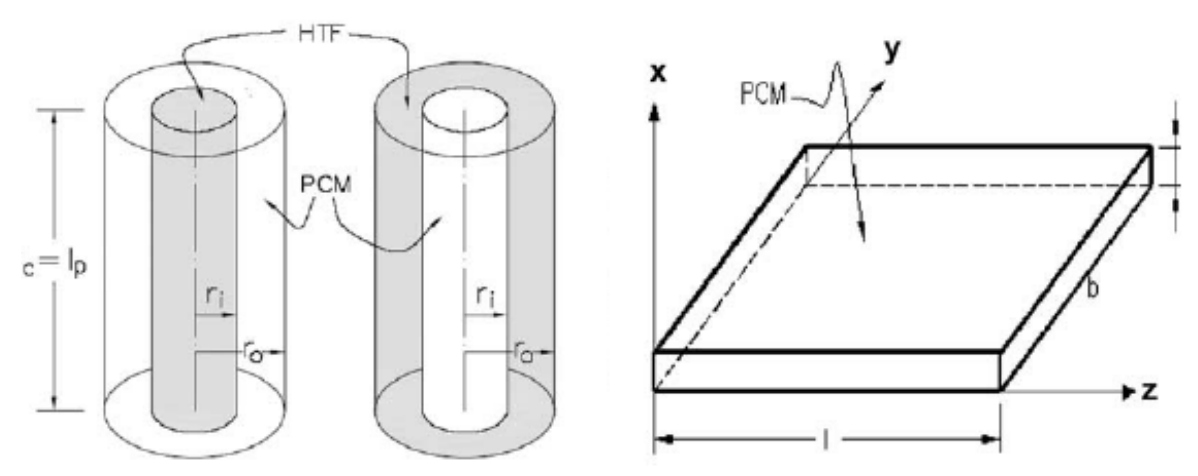

(b)

(c) 
3 Methods of improving the heat transfer performance between PCM and HTF also include the 4 increase of the thermal conduction inside PCMby adding highly thermal conductive particles, or metal 5 fins to overcome the weakness of intrinsiclow thermal conductivity of PCMs[47,63].There are a lot of 6 studies using finned tubes of various configurations [64-72]. Other approaches seen in the literature 7 include: bubble agitation [73], carbon fiber brushes for increasing the thermal conductivity of PCM 8 [74], insertion of a metal matrixinto the PCM [2,75-77], dispersing highconductivity particles into 9 PCM [78], micro/macro encapsulation of the PCM[79,80] or shell-and-tube packaging [81,82]. Figure 10 5shows configurations of PCM packaging mentioned above for the purpose of heat transfer 11 enhancement. 


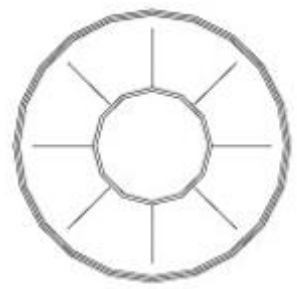

(i) Axial fins

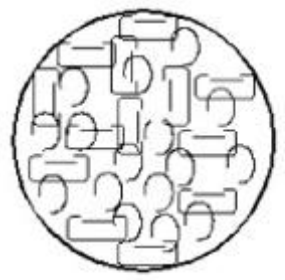

(v) Metal rings

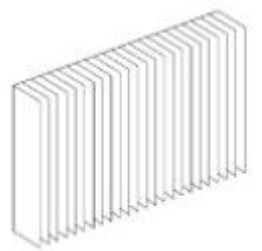

(ix) Finned Rectangular container

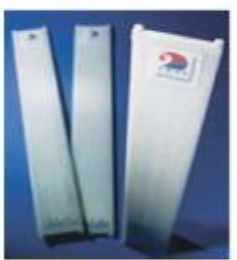

(xiii) Polypropylene

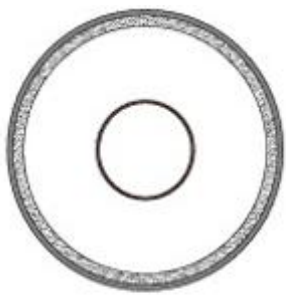

(ii) Circular fins

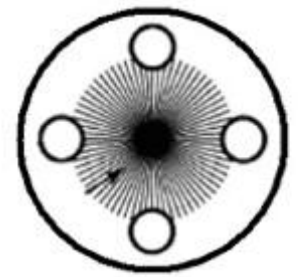

(vi) Carbon brushes

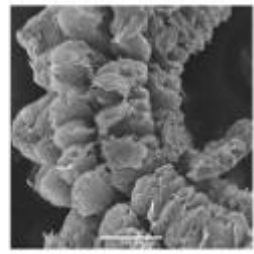

(x) Graphite flakes

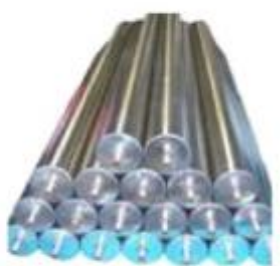

(xiv) Module beam

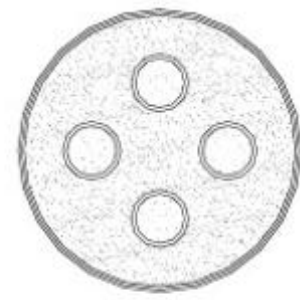

(iii) Shell and tube

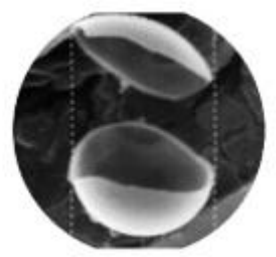

(vii) Encapsulation

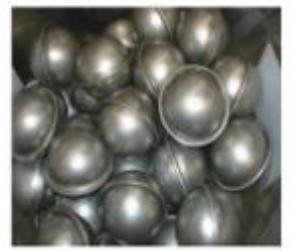

(xi) Steel ball capsules

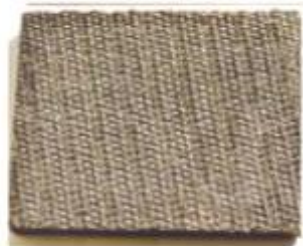

(xv) PCM graphite

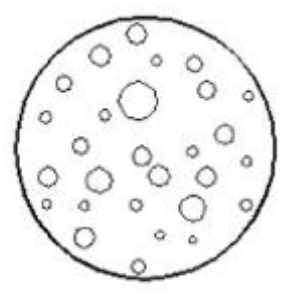

(iv) Bubble agitation

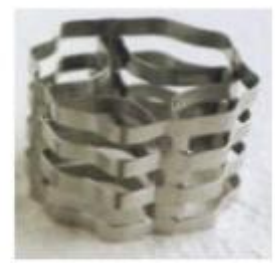

(viii) Metal matrix

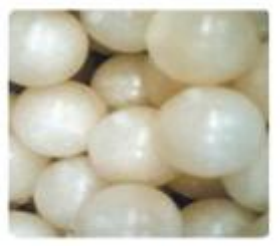

(xii) Polyolefin spherical balls

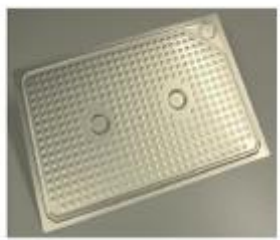

(xvi) Compact flat panel

Fig. 5. PCM packaging configurations to enhance heat transfer. [62]

In all the technologies shown in Fig. 5, bubble agitation and carbon fiber brushes are probably the two that need more explanations.Velraj et al. [73] did experiments to study the heat transfer enhancement in a LHTES system using bubble agitation, as shown in Fig. 5 (iv).In their study a very small amount of water was poured into the tube. Molten paraffin was then added and the tube was evacuated by a vacuum pump. The vacuum was maintained such that the saturation temperature of the water inside the tube was nearly equal to the phase change temperature of the PCM. The intention was to create steam bubbles inside the PCM during the phase change that would promote the heat transfer.Fukai et al. [74] developed brushes made of carbon fibers to improve the thermal 
1

2

conductivities of phase change materials, as shown in Fig. 6. The volume fraction of the fibers was accurately and easily controlled and that the fibers with a low volume fraction $(<1$ vol.\%) were entirely dispersed in the PCMs. They used the brushes to improve the thermal responses in the PCMs packed into cylindrical capsules and experimentally demonstrated that the effective thermal conductivities of the fiber/PCM composites reach the maximum values as theoretically predicted.

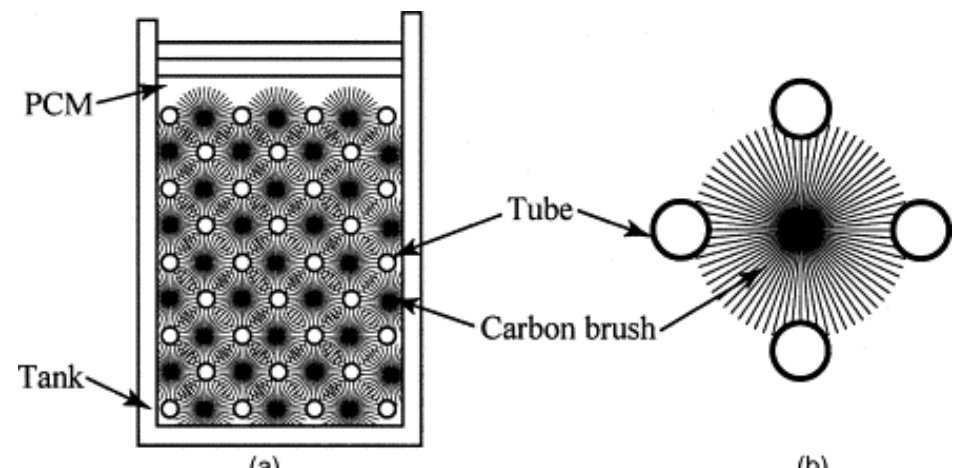

(a)

(b)

Fig. 6. Thermal energy storage units where brushes made of carbon fibers are inserted. [74]

The encapsulation of PCM has been given a lot of attentions during the recent time. If PCM is encapsulated into large number of capsules, either spheres or cylinders [83], the heat transfer area of PCM dramatically increases, which offers much better heat transfer when HTFflows through the capsulepacked bed. It has been reported that PCM stored in capsules with a radius of $10 \mathrm{~mm}$ offers a surface area of more than 300 square meters per cubic meter [84].Depending on the techniques of encapsulation, capsules may have a size of several tens of millimeters to sub-millimeters. Metallic encapsulation is preferred if high temperature is thecriterion, otherwise plastic encapsulation iscommonly used for low temperature application. Encapsulation techniques have been reported in the works by RUBITHERMTechnologies GmbH[85] and Climator Sweden AB [86].

Although making micro-encapsulated PCM is more challenging than that of making macro-encapsulated PCM, microencapsulation (of low temperature PCM using plastic shells)is still worth putting an effort, due to the fact that a substantially higher surface area to volume ratio is made possible when the capsule size goes down $[62,87,88]$. The difference of melting process of micro-encapsulated PCM with that of macro-encapsulated PCM was observed in the literature 
1 [89].Interestingly, there are also studies on the nano-encapsulated PCM forthermal energy storage

2 [90-93]. Table 6listed some surveyed detail of encapsulation and shell materials of capsules for PCMs.

3

4 Table 6 Manufacturers and their specifications of encapsulation of PCMs with maximum operating

5 temperature above $100{ }^{\circ} \mathrm{C}$

\begin{tabular}{|c|c|c|c|c|c|c|c|}
\hline Manufacturer & PCM & $\begin{array}{c}\text { Shell } \\
\text { material }\end{array}$ & Container & $\begin{array}{c}\text { Averagecontainer } \\
\text { size }\end{array}$ & Applications & $\begin{array}{c}\text { Operating } \\
\text { Temperature }\end{array}$ & Reference \\
\hline TEAP & $\begin{array}{l}\text { Glauber's salt, soda } \\
\text { ash, sodium acetate } \\
\text { and paraffin wax }\end{array}$ & $\begin{array}{l}\text { Aluminum, } \\
\text { steel and } \\
\text { polyethylene }\end{array}$ & Bottles, balls & $25.4 \mathrm{~mm}$ & $\begin{array}{l}\text { Storage and transport of } \\
\text { food,medical equipment, } \\
\text { storage, materials for textile }\end{array}$ & $25^{\circ} \mathrm{C}-100^{\circ} \mathrm{C}$ & [94] \\
\hline $\begin{array}{c}\text { Rubitherm } \\
\text { GmbH }\end{array}$ & $\begin{array}{l}\text { Paraffin, salt hydrate } \\
\text { in } \\
\text { granulate, powder and } \\
\text { compound forms }\end{array}$ & $\begin{array}{l}\text { Aluminum, } \\
\text { plastic }\end{array}$ & Box, bag & N/A & $\begin{array}{l}\text { Storage and transport of } \\
\text { food,medical equipment, } \\
\text { storage, materials for textile }\end{array}$ & $30^{\circ} \mathrm{C}-100^{\circ} \mathrm{C}$ & [85] \\
\hline $\begin{array}{l}\text { PCM Products } \\
\text { Ltd. }\end{array}$ & $\begin{array}{c}\text { Eutectics, salt } \\
\text { hydrates, } \\
\text { organic materials, and } \\
\text { high temperature salts }\end{array}$ & $\begin{array}{c}\text { Rubber, } \\
\text { HDPE plastic }\end{array}$ & $\begin{array}{c}\text { Tube, ball, } \\
\text { pouches,plate }\end{array}$ & $40 \mathrm{~mm}$ & $\begin{array}{c}\text { International space } \\
\text { station, automotive passive } \\
\text { cooling, solarheating and heat } \\
\text { recovery }\end{array}$ & $90^{\circ} \mathrm{C}-885^{\circ} \mathrm{C}$ & [56] \\
\hline $\begin{array}{l}\text { MicrotekLab. } \\
\text { Inc. }\end{array}$ & Paraffin & Polymer & N/A & $\begin{array}{l}17-20 \mu \mathrm{m} \\
3-5 \mathrm{~mm}\end{array}$ & $\begin{array}{l}\text { Active wear clothing, woven } \\
\text { andnon-woven textiles, } \\
\text { buildingmaterials, packaging, } \\
\text { electronics }\end{array}$ & $25^{\circ} \mathrm{C}-250^{\circ} \mathrm{C}$ & [95] \\
\hline
\end{tabular}

(Note: N/A means it is not reported on the company's website.)

\subsection{Recent development of PCM encapsulation technologies}

It is critical to ensure that thecapsules having no leakage of liquid PCM when it is melt. Regin et al. [2], Nath [96] and Nomura [97] summarized the functions and requirements of materials to contain PCM: (i) meeting therequirements of strength, flexibility, corrosion resistance, and thermal stability; (ii) acting as a barrier toprotect the PCM from harmful interactions with the heat transfer fluid surrounding PCM capsules; (iii)capsules are relatively small to have large surface-to-volume ratio, providing sufficient heat transfersurface area; (iv) providing structural stability and easy handling.

In order to make PCM capsules having the above characteristics, two different approaches can beadopted [96]. One is to make a PCM pellet of desired shape, either spherical or cylindrical and thenapply a coating or a series of coatings which acts as a shell to hold the PCM inside. The other approachis to fabricate a shell (cylindrical or spherical) first and then fill in with PCM. The diagram in 
Fig. 7shows the two categories of PCM encapsulation technology.

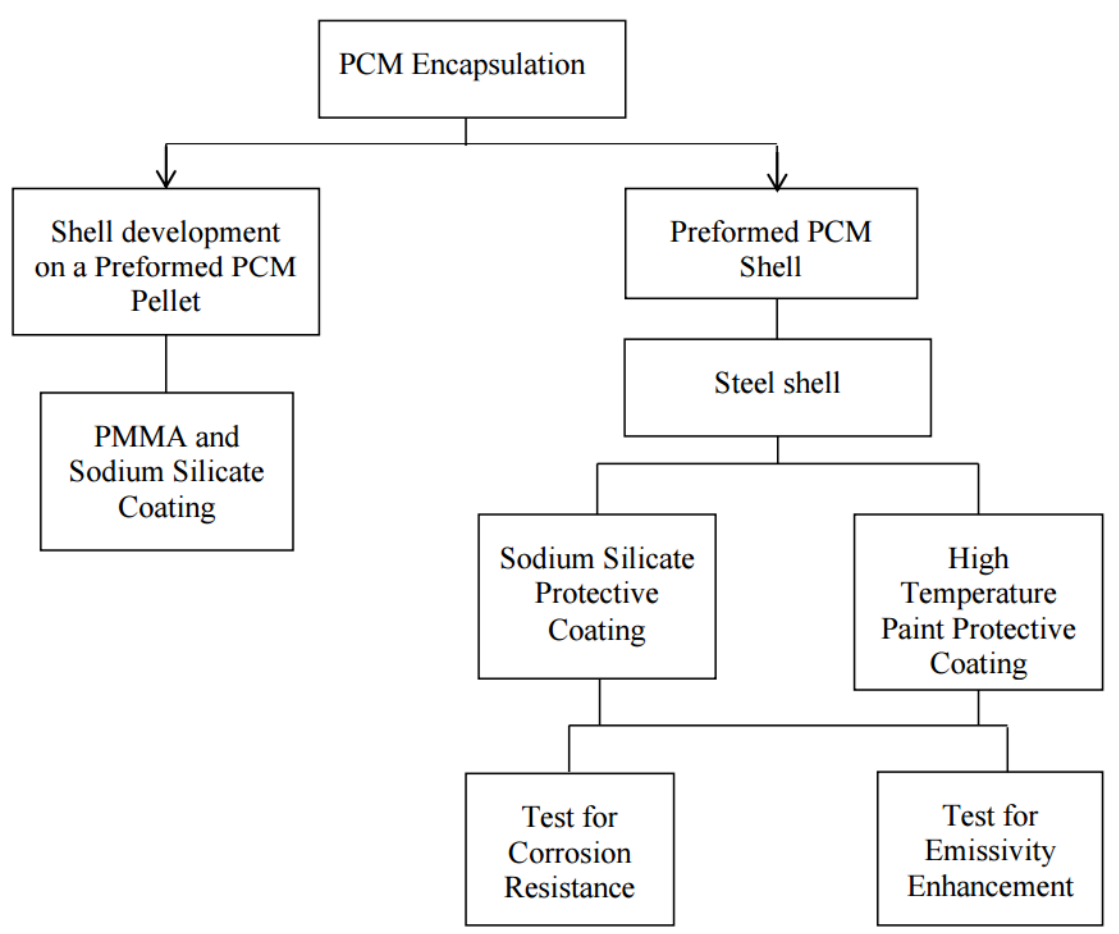

Fig. 7 Schematic of Steps to Develop PCM Encapsulation. [96]

Due to the recent development of encapsulation technology, the size of PCM capsules can coverthe range from 1-2 centimeters (macro-size) down to micrometers. Conventional PCM capsules aremostly in macro size.There are a number of published papers that reported various shell materials suchas metals and plastics, and various shapes such as spherical[ 98-102]and cylindrical [99, $103-105]$.Micro-encapsulation of PCM is a technology getting significant attention recently[106-111]for the advantage of getting larger surface area-to-volume ratio and alsobetter adaptation to thermal expansion/contraction during phase change processes [106,107].A numberof papers reported the encapsulation methods, core PCM materials, shell materials, thermophysical properties, and capsule sizes of various micro capsules. Micro-interfacial polymerization [107] and in-situ poly-condensation [108-111] are the most popular micro-encapsulation methods.Medium to high temperature PCM encapsulation usually needs metal shells. Maruoka and Akiyama [112] proposed the encapsulation of using spherical metal shell, such as $\mathrm{Cu}$ and $\mathrm{Pb}$ with an electroplated $\mathrm{Ni}$ layer. 

In summary, the technology of encapsulation of low-temperature PCMs is getting a significantdevelopment, in particular, the micro-encapsulated PCMs is becoming increasingly popular. Theencapsulation of high-temperature PCMs is very challenging and thus is less popular despite itsengineering importance. In the near future, it is expected that easy-producible encapsulatedhigh-temperature PCMs with large thermal density for the purpose of CSP application will bedeveloped.

\section{Current status of research and application ofLHTESsystemsfor CSP plants}

\subsection{Brief introduction to CSP technologies with incorporation of energy storage}

CSP technology dates back to 1970s, but most of the commercial CSP installations were only made in this decade, particularly in Spain and the USA [16,17]. Four well-known CSP technologies are: parabolic trough collectors (PTC), linear Fresnel reflectors (LFR), solar power tower (SPT), and parabolic dish systems (PDS). Among these technologies, PTC is the most common one, which takes more than $95 \%$ of the global CSP installations.

CSP technology has made great progresses recently. Only in 2014, there were five CSP plants in the world completed[113].National Renewable Energy Laboratory (NREL) has a webpage giving details of all the CSP plants in operation around the worldup to date [8]. Table 7 lists the detailed information of the CSP plants with TES systemsin full commission operation since 2010 inUSA and Spain.

21 Table 7. Summary of CSP plants in operation since 2010 in U.S. and Spain. [8]

\begin{tabular}{|c|c|c|c|c|c|c|c|c|}
\hline Country & Project Name & $\begin{array}{c}\text { Capacity } \\
\text { (MW) }\end{array}$ & CSP type & HTF & $\begin{array}{c}\text { Commission } \\
\text { Date }\end{array}$ & TES & $\begin{array}{c}\text { Storage } \\
\text { Type }\end{array}$ & $\begin{array}{c}\text { Operating } \\
\text { Temperature }\end{array}$ \\
\hline USA & $\begin{array}{c}\text { Solana Generating } \\
\text { Station }\end{array}$ & 250 & PTC & Therminol VP-1 & 2013 & $\begin{array}{c}6 \text { h capacity } 2 \text {-tank indirect storage } \\
\text { with molten salts }\end{array}$ & SHTES & $293{ }^{\circ} \mathrm{C}-393{ }^{\circ} \mathrm{C}$ \\
\hline USA & $\begin{array}{l}\text { Crescent Dunes } \\
\text { Solar Energy }\end{array}$ & 110 & SPT & Molten salts & 2013 & $\begin{array}{l}10 \text { h capacity } 2 \text {-tank direct storage } \\
\text { with molten salts }\end{array}$ & SHTES & $288^{\circ} \mathrm{C}-565^{\circ} \mathrm{C}$ \\
\hline Spain & $\begin{array}{l}\text { Andasol Solar } \\
\text { Power Station }\end{array}$ & 150 & PTC & $\begin{array}{l}\text { Dowtherm } \\
\text { A/Thermal oil }\end{array}$ & $2008-2011$ & $\begin{array}{c}7.5 \text { h capacity } 2 \text {-tank indirect } \\
\text { storage with Solar Salt }\end{array}$ & SHTES & $293{ }^{\circ} \mathrm{C}-393{ }^{\circ} \mathrm{C}$ \\
\hline Spain & Arcosol 50 & 50 & PTC & $\begin{array}{l}\text { Biphenyl/Diphenyl } \\
\text { oxide }\end{array}$ & 2011 & $\begin{array}{c}7.5 \text { h capacity } 2 \text {-tank indirect } \\
\text { storage with Solar Salt }\end{array}$ & SHTES & $293{ }^{\circ} \mathrm{C}-393{ }^{\circ} \mathrm{C}$ \\
\hline Spain & Arenales & 50 & PTC & Diphyl & 2013 & $\begin{array}{c}7 \text { h capacity } 2 \text {-tank indirect storage } \\
\text { with Solar Salt }\end{array}$ & SHTES & $293^{\circ} \mathrm{C}-393^{\circ} \mathrm{C}$ \\
\hline
\end{tabular}




\begin{tabular}{|c|c|c|c|c|c|c|c|c|}
\hline Spain & $\begin{array}{c}\text { Aste Solar Power } \\
\text { Station }\end{array}$ & 100 & PTC & Dowtherm A & 2012 & $\begin{array}{c}8 \mathrm{~h} \text { capacity } 2 \text {-tank indirect storage } \\
\text { with Solar Salt }\end{array}$ & SHTES & $293^{\circ} \mathrm{C}-393^{\circ} \mathrm{C}$ \\
\hline Spain & Astexol II & 50 & PTC & Thermal oil & 2012 & $\begin{array}{c}8 \mathrm{~h} \text { capacity } 2 \text {-tank indirect storage } \\
\text { with Solar Salt }\end{array}$ & SHTES & $293^{\circ} \mathrm{C}-393^{\circ} \mathrm{C}$ \\
\hline Spain & Casablanca & 50 & PTC & $\begin{array}{l}\text { Biphenyl/Diphenyl } \\
\text { oxide }\end{array}$ & 2013 & $\begin{array}{l}7.5 \text { h capacity 2-tank indirect } \\
\text { storage with Solar Salt }\end{array}$ & SHTES & $293^{\circ} \mathrm{C}-393^{\circ} \mathrm{C}$ \\
\hline Spain & Extresol & 150 & PTC & $\begin{array}{l}\text { Biphenyl/Diphenyl } \\
\text { oxide }\end{array}$ & $2010-2012$ & $\begin{array}{l}7.5 \text { h capacity } 2 \text {-tank indirect } \\
\text { storage with Solar Salt }\end{array}$ & SHTES & $293^{\circ} \mathrm{C}-393^{\circ} \mathrm{C}$ \\
\hline Spain & $\begin{array}{c}\text { Gemasolar } \\
\text { Thermosolar Plant }\end{array}$ & 20 & SPT & Solar Salt & 2011 & $\begin{array}{l}15 \mathrm{~h} \text { capacity } 2 \text {-tank direct with } \\
\text { Solar Salt }\end{array}$ & SHTES & $290^{\circ} \mathrm{C}-565^{\circ} \mathrm{C}$ \\
\hline Spain & La Africana & 50 & PTC & Undefined & 2012 & $\begin{array}{l}7.5 \text { h capacity 2-tank indirect } \\
\text { storage with Solar Salt }\end{array}$ & SHTES & $293^{\circ} \mathrm{C}-393^{\circ} \mathrm{C}$ \\
\hline Spain & La Dehesa & 50 & PTC & $\begin{array}{l}\text { Biphenyl/Diphenyl } \\
\text { oxide }\end{array}$ & 2011 & $\begin{array}{l}7.5 \text { h capacity 2-tank indirect } \\
\text { storage with Solar Salt }\end{array}$ & SHTES & $298^{\circ} \mathrm{C}-393^{\circ} \mathrm{C}$ \\
\hline Spain & La Florida & 50 & PTC & $\begin{array}{l}\text { Biphenyl/Diphenyl } \\
\text { oxide }\end{array}$ & 2010 & $\begin{array}{l}7.5 \text { h capacity 2-tank indirect } \\
\text { storage with Solar Salt }\end{array}$ & SHTES & $298^{\circ} \mathrm{C}-393^{\circ} \mathrm{C}$ \\
\hline Spain & Manchasol & 100 & PTC & $\begin{array}{l}\text { Biphenyl/Diphenyl } \\
\text { oxide }\end{array}$ & 2011 & $\begin{array}{l}7.5 \mathrm{~h} \text { capacity } 2 \text {-tank indirect } \\
\text { storage with Solar Salt }\end{array}$ & SHTES & $293^{\circ} \mathrm{C}-393^{\circ} \mathrm{C}$ \\
\hline Spain & Termesol 50 & 50 & PTC & $\begin{array}{l}\text { Biphenyl/Diphenyl } \\
\text { oxide }\end{array}$ & 2011 & $\begin{array}{l}7.5 \text { h capacity } 2 \text {-tank indirect } \\
\text { storage with Solar Salt }\end{array}$ & SHTES & $293^{\circ} \mathrm{C}-393^{\circ} \mathrm{C}$ \\
\hline Spain & Termosol & 100 & PTC & Thermal oil & 2013 & $\begin{array}{l}9 \mathrm{~h} \text { capacity } 2 \text {-tank indirect storage } \\
\text { with Solar Salt }\end{array}$ & SHTES & $293^{\circ} \mathrm{C}-393^{\circ} \mathrm{C}$ \\
\hline
\end{tabular}

1 (Note: All information is from NREL website of Concentrated Solar Power Project Profiles.)

2

3 3.2. Recent developments of LHTES system in CSP applications

4 As indicated in Table 7, Solar SaltSHTESis utilized in most of CSP plants. Obviously,

5 LHTESusing high temperature PCM is not popular yet for commercialized CSP plants. The reason is

6 that the more challenging techniques of high temperature PCM encapsulation and heat transfer

7 enhancement are still undergoing research and development $[2,96,114]$. However, as observed from

8 Table 7, if PCM is adopted as the storage media in commercialized CSP plants, the operating

9 temperatures will be the same from $293{ }^{\circ} \mathrm{C}$ to $393{ }^{\circ} \mathrm{C}$ based on the Rankine power cycle. It is also

10 worth noting that PCM with higher melting temperature is always desirable in CSP plants with higher

11 operating temperature $\left(>600^{\circ} \mathrm{C}\right)$ due to the requirement of higher energy conversion efficiency.

12 In the recent 10 years, however, there are still quite amount of research and development for high

13 temperature LHTES systems. The German Aerospace Centre (DLR) did intensive research

14 toinvestigate Sodium Nitrate $\left(\mathrm{NaNO}_{3}\right)$ as a latent-heat thermal storage medium in the temperature 


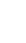

range from $296{ }^{\circ} \mathrm{C}$ to $316{ }^{\circ} \mathrm{C}$. They used $\mathrm{NaNO}_{3}$ for thermal storage in a direct steam CSP plant. Acting as a heat transfer fluid, the steam generated in solar field has a pressure of around 100 bar that passes through a thermal storage tank and gives out heat for storage. Laing et al. from DLR[115] testeda prototype storage tankwith $140 \mathrm{~kg}$ of $\mathrm{NaNO}_{3}$ as storage media and steam as HTF, and seven steel tubeswith aluminum fins were imbedded in the tank, as shown in Fig. 8. This is the shell-and-tube type of packing configuration. They operated the thermal storage system for 172 cycles (more than 4000 hours) from $296{ }^{\circ} \mathrm{C}$ to $316^{\circ} \mathrm{C}$, and proved no decomposition of the PCM and no degradation of the finned aluminum steam tubes.

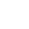
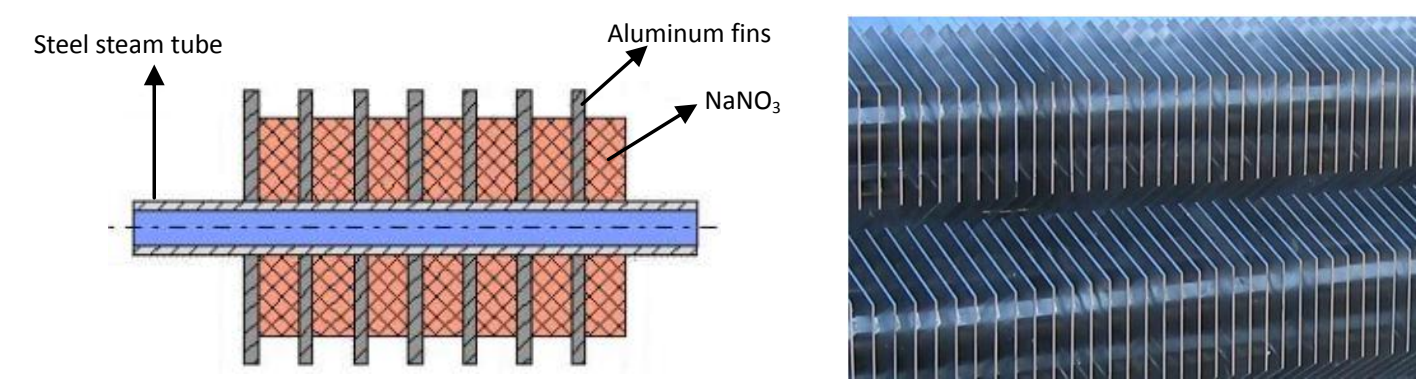

Fig. 8Schematic of the $\mathrm{NaNO}_{3}$ test module with steel fins attached on the steam tube,[115]

The storage module in Fig. 8was then scaled up to a unit having 14 tons of $\mathrm{NaNO}_{3}$ by Laing et al. [116].The PCM modules were combined with two concrete sensible thermal storage modules in a direct steam generation facility in Spain under real operation conditions, and the two concrete sensible thermal storage modules were used to store the heat for preheating and superheatingof the water/steam, as shown in Fig. 9. Such a test facilitydemonstrated the sandwich concept of enhancement of heat transfer as a possibility to achieve high dischargepower even at elevated temperatures, in spite of the low heatconductivity of PCMs. After 172 cycles in the temperature range from $25{ }^{\circ} \mathrm{C}$ to $400{ }^{\circ} \mathrm{C}$, no degradation of PCMs was detected. 


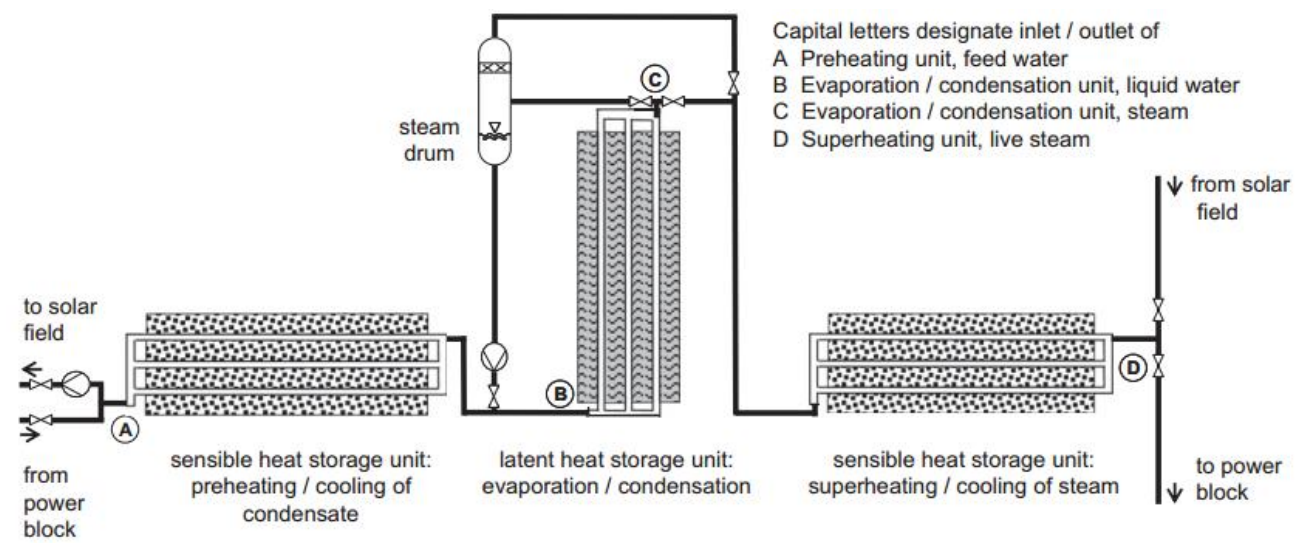

Fig. 9Overview of a three-part thermal energy storage system for Direct Steam Generation (DSG) combining sensible and latent heat storage. [116]

Adinberg et al. [117] tested a reflux heat transfer storage (RHTS) system with PCM, as shown in Fig. 10. The concept of reflux heat transfer storage is based on the reflux evaporation-condensation occurring in the intermediate HTF. In their experiments, the discharge and charge heat exchangers were placed at the top and the bottom of the storage unit, and the charge heat exchanger was also immersed in the liquid intermediate HTF. They used Sodium Chloride $(\mathrm{NaCl})$ as the PCM and sodium metal as the intermediate heat transfer medium for a storage temperature of $800{ }^{\circ} \mathrm{C}$. A metal alloy $\mathrm{Zn}-\mathrm{Sn}$ (70-30wt $\%$ ) and the eutectic mixture of $26.5 \%$ biphenyl and $73.5 \%$ diphenyl oxide were experimentally investigated as the PCM-HTF system for producing high-temperature superheated steam in the temperature range of $350^{\circ} \mathrm{C}-400^{\circ} \mathrm{C}$ [117]. Although the proposed $\mathrm{Zn}-\mathrm{Sn}(70-30 \mathrm{wt} \%)$ PCM ismuch more expensive than any of the molten salts, RHTS applications can probably be rewarding as the end result of a significantly improved thermal storage performance based on outstanding chemical stability, superior thermal conductivity and high heat transfer.

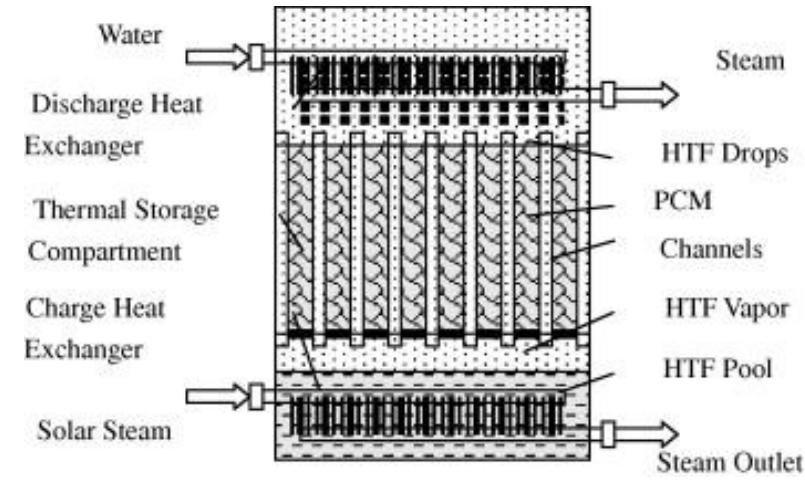

Fig. 10 Schematic diagram of the reflux heat transfer storage concept [117]. 
A TES system employing multiple PCMs with different melting temperatures is another attractive

3

4

5

6

7

heat transfer enhancement technology. In this type of system, a few modules containing different PCMs with different melting temperatures are connected to each other in series. The multiple PCMs in shell-and-tube units should be in the flow direction that the melting temperature decreases in the charging process and increases in the discharging process as illustrated in Fig. 11 [118].

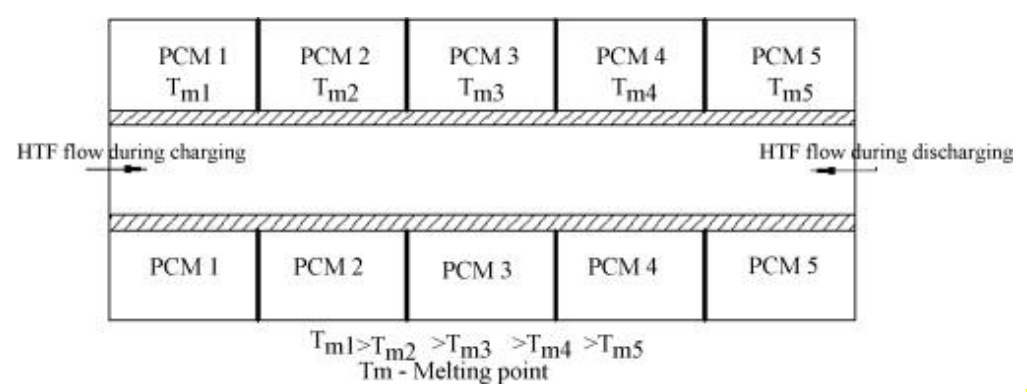

Fig. 11. Sequence of multiple PCMs in shell and tube latent heat storage unit [118]

Michels and Pitz-Paal [119] designed and tested a vertical shell-and-tube heat storage system filled with three high temperature $\mathrm{PCMs} \mathrm{KNO}_{3}(\mathrm{PCM}-1)$, eutectic $\mathrm{KNO}_{3} / \mathrm{KCl}(\mathrm{PCM}-2)$, and $\mathrm{NaNO}_{3}$ (PCM-3). Fig.12 shows the schematic of the experimental setup and a picture of multiple-PCM thermal storage unit. The experimental results showed that around 92\% of the PCM in the multiple-PCM storage unit was completely molten at the end of charging and around $67 \%$ was completely solidified at the end of discharging. In the single storage unit containing $\mathrm{NaNO}_{3}$ as the PCM, almost $100 \%$ of the PCM was completely molten at the end of charging but only $2 \%$ was completely solidified at end of discharging. They found that multiple-PCM storage unit can offer a higher utilization of the possible phase change, and a more uniform HTF outlet temperature and higher exergy efficiency. 

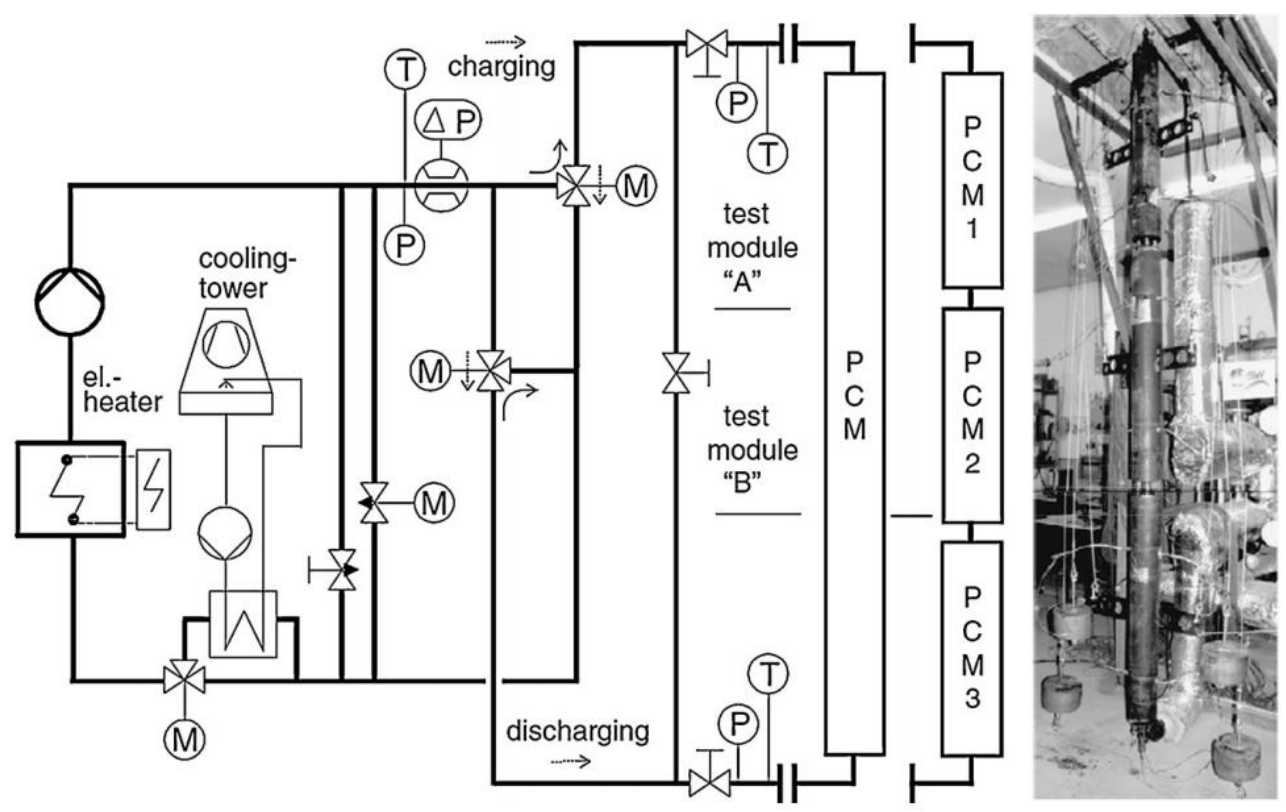

1

2

3

4

5

6

Fig. 12. Schematic diagram of experimental set up and a picture of multiple PCM storage system [119]

Due to the complexity of LHTES system, parametric study to LHTES system has to be conducted first in order to further improve the thermal storage efficiency of latent heat storage system. Since 2005, only one research paper reporting the parametric study for high temperature LHTES system. Guo and Zhang [120] conductedparametric study to assess how the thermal storage performance isaffected by the geometry, thermal and boundary conditions in a shell-and-tube LHTES system. Their computational results illustrated how the heat transfer and discharge time were affected by the changes in geometry of the aluminum fins, tube radius, boundary conditions, and thermal conductivity of the PCM. It is expected that more thorough investigations including the thermal properties of PCM and the operating parameters of thermal storage systemwill be conducted.

The SunShot program from Department of Energy of the U.S. has funded a number of projects to develop high temperature PCM-basedLHTES system for CSP plants. It is hopedthat a better PCM-based LHTES system will be applied in commercialized CSP plant in the future, after conducting thorough parametric studies, solid systematic optimization, and pilot-scale systemtests.

\subsection{Analysis of energy storage efficiency ofLHTES system}

The performance of a TES system can be evaluated through an energy storage efficiency. As far as LHTES systems are concerned, the efficiency is a measure of how effectively the heat can be stored or 
recovered. Hence, the efficiency of a LHTES system can be determined as charging efficiency or discharge efficiency or overall (complete cycle) efficiency.

Many investigators have analyzed the efficiency of LHTES systems. These investigations were either for a charging or a discharging process separately, or the complete working cycles of the system. The influence of various design and operating parameters on the efficiency has been studied.

Seeniraj et al. [121] investigated the thermal performance of a shell-and-tube LHTES unit. The thermal performance was studied using a quantity which is the ratio between the total heat stored and the maximum latent heat that can be stored.

If the HTF in a thermal storage system can be withdrawn at the temperature that it was originally stored, then the system has the highest energy storage efficiency from the thermodynamics point of view. Based on the work of $\mathrm{Li}$ et al. [122], the energy delivered in the required time period from a latent heat storage system is always less than that of the energy charged to the tank. If the required heat discharging period is $t_{\text {ref,discharge }}$, then a round-trip energy efficiency can be defined as:

$$
\xi_{\text {trip }}=\frac{\int_{0}^{t_{\text {tef,discharging }}} \rho_{f} C_{f}\left[T_{f}(z=H, t)-T_{L}\right] d t}{\rho_{f} C_{f}\left(T_{H}-T_{L}\right) \cdot t_{\text {ref,discharging }}}
$$

where the numerator represents the energy discharged from the storage tank, and the denominator represents the energy charged to the tank in the same time period as that of discharging.

Other than the round trip energy efficiency, energy storage efficiency may be defined by accounting the energy inside the storage system at the beginning and end of energy charging and discharging. Based on the enthalpy distributions $h_{r}$ of PCM at the end of charge/discharge, Xu et al. [123] defined the energy storage efficiency:

$$
\xi_{\text {storage }}=\frac{\int_{0}^{H}\left[h_{r}\left(z, t=t_{\text {ref,charging }}\right)-h_{r}\left(z, t=t_{\text {ref,discharging }}\right)\right] d z}{\int_{0}^{H}\left[h_{r}\left(z, t=t_{\text {ref,charging }}\right)\right] d z}
$$

It is important to note that the thermal performance of LHTES system is assessed using only energy, which is based on first law of thermodynamics to identify the ways to improve the quantity of heat stored/recovered. However, the primary purpose of a thermal energy storage system is not to store the energy, rather to store useful work. As a consequence, energy analysis does not reflect the quality of energy stored/recovered. This inadequacy can be overcome, if an analysis based on second law of 
thermodynamics is carried out for LHTES system, which will be introduced in next section.

\subsection{Exergy analysis of LHTES system}

Exergy analysis is a method that uses the conservation of mass and energy principles together with the second law of thermodynamics for the design and analysis of energy systems. It can reveal whether or not it is possible to design more efficient energy systems by reducing inefficiencies [124]. The exergy analysis method can provide information on the quality of the energy transferred in LHTES systems [124].

In 1980s and 1990s, Bjurström and Carlsson [125] as well as Adebiyi and Russell [126], determined an optimum melting temperature for the PCM that would maximize the second-law efficiency during charging. Both studies concluded that maximum exergy would be recovered from the HTF when the melting temperature of PCM is equal to the geometric average of the environment temperature and the temperature of the hot HTF during charging. De Lucia and Bejan [127] accounted for the effect of natural convection during PCM melting, and they found the same expression for the optimal temperature as in Refs. [125] and [126].

There are quite amount of research papers discussing exergy analysis to LHTES systems since 2010. Jegadheeswaran et al. [128] presented a thorough review of the exergy analysis of LHTES systems. Keshavarz et al. [129] and Li et al. [130] investigated multiple PCMs in cascaded configurations in order to either minimize the entropy generation during an entire charging/discharging cycle, or to maximize the exergy extracted during discharging. Mahfuz et al. [131] performed energy and exergy analysis for a CSP plant located in Shiraz, Iran. They analyzed the exergy efficiency to show the possible improvement of efficiencies by integrating PCM. It was found that the exergy efficiency was only about $10 \%$ without using PCMs, but the exergy efficiency can be improved to $30 \%$ if PCM was adopted as the storage medium. Shabgard et al. [132] performed a combined heat transfer and exergy analysis to quantify the performance of a LHTES system. In order to maximize the exergy extracted from the storage system, a specific melting temperature must be used in conjunction with a specific charging time period and a specific HTF inlet temperature during discharging. For a typical molten salt PCM, the optimal melting temperatures corresponding to charging HTF inlet temperatures of $560^{\circ} \mathrm{C}$ and $800^{\circ} \mathrm{C}$ are $475^{\circ} \mathrm{C}$ and $715^{\circ} \mathrm{C}$, respectively. 

PCMTES) system and a HP-TES (TES withembedded heat pipes)for Rankine cycle and

$3 \mathrm{~s}-\mathrm{CO}_{2}$ (supercritical carbon-dioxide) power cycles.For a CSP plant operating on $\mathrm{s}-\mathrm{CO}_{2}$ power cycle, 4 theexergetic efficiencies of the EPCM-TES were simulated at tank heights of $10 \mathrm{~m}$ and $20 \mathrm{~m}$, with 5 different tankradius and radius of PCM capsules. Fig.13(a)and (b) showsthat the exergetic efficiency of 6 EPCM-TESis higher with largerstorage tank radius at a fixed mass flow of HTF and capsule radius.

7 The decrease in EPCM-TES tank radius leadsto an increase in HTF velocity, resulting in a decrease in 8 the residencetime of the HTF in the tank. Consequently, the exergetic efficiencyis low for cases withsmalltank radius.Fig. 13 (c) and (d) show the exergetic efficiency of ECPM-TESsystem working

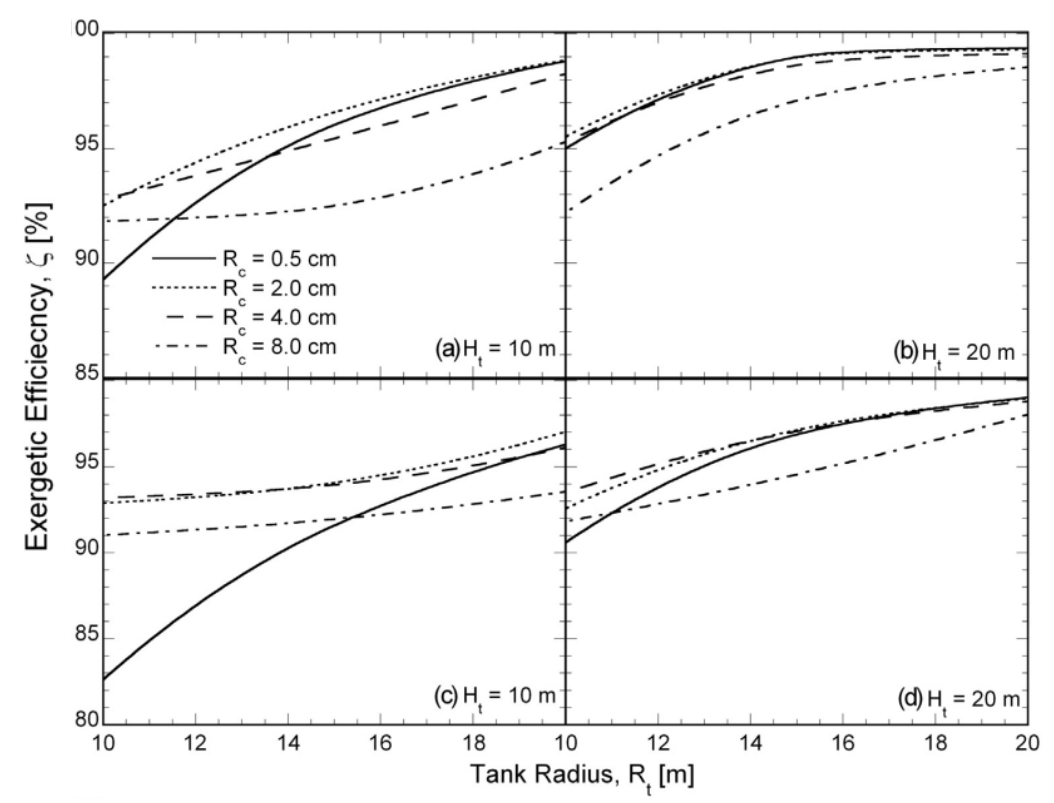

Fig. 13 Exergetic efficiency at conditions of different combinations of tank radius and capsule radius. (a) tank height of $10 \mathrm{~m}$, and (b) tank height of $20 \mathrm{~m}$ forS-CO $\mathrm{CO}_{2}$ cycle. (c) tank height of $10 \mathrm{~m}$, and (d) tank height of $20 \mathrm{~m}$ for a Rankine cycle. [133] 

inlet temperature of HTF should be selected.During charging, higher inlet temperature of HTF leads to higher temperature difference between $\mathrm{HTF}$ and PCM, which also results in higher entropy generation.This conclusion was proven by Kousksou et al. [134] when they analyzed a packed-bed encapsulated PCM storage system.As a result, one may conclude that in order to minimize entropy generation, the HTF inlet temperature should be as close as possible to the melting temperature of PCM. However, smaller temperature difference results in lower heat transfer rate and the charging rate. Hence, the selection of HTF inlet temperature may be a compromise between the required charging rate and exergy performance.Erek and Dincer [135] have calculated exergy efficiency for a shell-and-tube storage module, and they have found significant increase of exergy efficiency due to increase in HTF inlet temperature during discharging.

The exergy performance of LHTES system is also found depending on mass flow rate of HTF. According to the conclusions from Kousksou et al. [134136] and Erek and Dincer [135], the temperature difference between inlet and outlet temperature of HTF decreases as Re number increases. and PCM. Therefore, the net exergy can be increased by increasing Re number,although there is an increase in pressure drop irreversibility.

Fig. 14 Comparison of energy recovery for cases using PCM and sensible heat storage method.Sensible heat storage allows high exergy recovery and high energy density simultaneously.

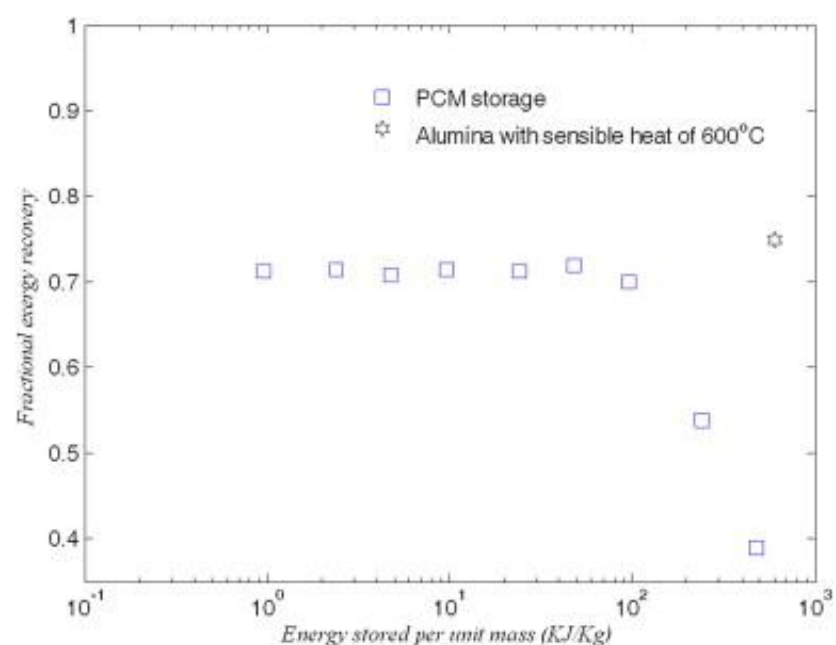


In 2013, Bindra et al. [137] reported that for a packed-bed storage system, SHTES can provide higher exergy recovery thanLHTES under similar high temperature conditions. In theirstudy, similar properties and operating conditions of HTF were applied. Particle size and shape for sensible heat storage material and PCM encapsulated material were chosen to be identical. The results of this comparative analysis are presented in Fig. 14, which shows that with sensible heat higher energy density and higher exergy recovery can be simultaneously achieved; whereas with PCM it is difficult to achieve both simultaneously. They also concluded that a PCM method is particularly useful if the heat is needed at a temperature near the melting temperature. Xu et al. [138] found similar phenomenon when they calculated and compared the thermal storage efficiency for a packed-bed TES system using different storage media.

Nevertheless, one cannot simply conclude that LHTES system is not as good as SHTES system, since systematic optimizations to LHTES system is needed to approach high efficiency. For example, based on Nithyanandam and Pitchumani's analysis [133], the round-trip exergy efficiency of LHTES system can approach 95\%, which is pretty close to the target set by DOE SunShot program. Nithyanandam and Pitchumani's work [133] is the first publication which demonstrates the exergy efficiency after the storage system is optimized. It is expected that more studies will discuss a fair comparison between systems using LHTES and SHTES.

\section{Mathematical modelingand numerical simulation to latent-heat thermal storage}

The heat transfer between the PCM and a HTF during the thermal charging and discharging processes needs to be analyzed in order to understand the time-dependent temperature variation of HTF when the stored heat is retrieved for utilization. In this section, mathematical models describing the heat transfer between PCM and HTF will be presented. Numerical methods and procedures of solution to the relevant governing equations will also be briefly discussed.

A one-dimensional mathematical model about the heat transfer between packed bed of encapsulated PCM and HTF is summarized here for readers to get a basic understanding. Thereafter, efforts and studies for more accurate and sophisticated modeling will be introduced.

As shown in Fig. 15, the thermal storage tank is packed with capsules of PCM, and heat transfer 
fluid flows through the packed bed.With no melting process considered, Schumann [139] proposed a group of governing equations early in 1929 for the heat transfer between packed bed of rocks and a HTF. For the heat transfer in melting process, we need a supplementary equation for the energy balance in the PCM. The following assumptions are necessary for the one-dimensional mathematical modeling.

1) There is a uniform radial distribution of the flow and filler material throughout the storage tank.

2) Assume that the capsules have only point contact between each other and therefore heat conduction between capsules is negligible.

3) In the HTF, compared to the convective heat transfer the heat conduction in the axial direction isignorable.

4) When the capsules have Biot numbers less than 0.1, the lumped heat capacitance method is basically applicable to the transient heat conduction in the capsules. For capsules with larger Biot number, a modified lumped capacitance method will be applied to, which is accomplished simply by introducing a modified heat transfer coefficient for the convection heat transfer between the fluid and the capsules.

5) It is assumed that the PCM is homogenous and isotropic, and there are no impurities inside the phase change material, resulting in the melting process being isothermal.

6) Heat loss from the storage tank to the surroundings is negligible.

7) The onset of natural convection in liquid PCM during phase changing process is determined bythe Rayleigh number (Ra). Due to the small size of encapsulated PCMs and its consequence ofrestricted moving capacity of liquid phase PCM inside the capsules, the Rayleigh number ofliquid PCM is sufficiently small for neglect of natural convection, which is the case in the presentstudy. However, it is worth noting that if the natural convection is significant, a common way toconsider the effect of heat transfer improvement inside PCM is to introduce an effective thermalconductivity to consider both the conduction and natural convection, which is discussed at the endof this section. As a result, the 1D model introduced in this section also preserves the capability ofconsidering the natural convection in encapsulated PCM during the phase changing process. 


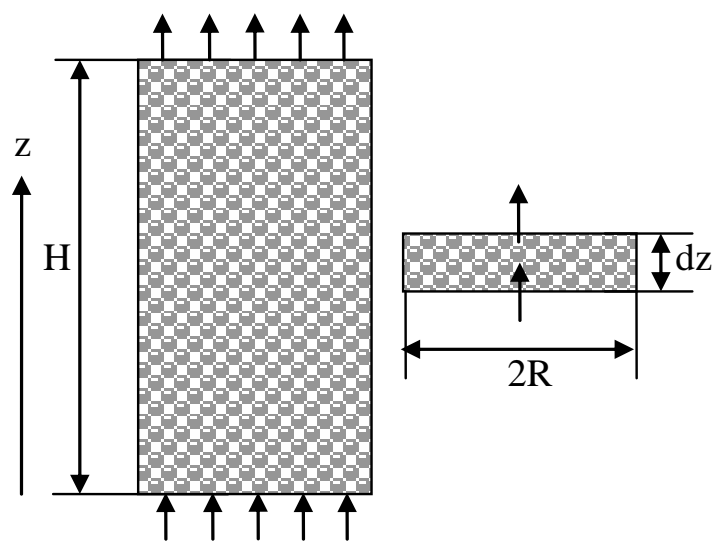

Fig. 15 A differential control volume of the packed bed of capsules

When there is no phase change, the energy balance equations for the HTF and the capsules due to the heat exchange between capsules and HTF are as follows:

$$
\begin{gathered}
\frac{h S_{s}}{\rho_{f} C_{f} \varepsilon \pi R^{2}}\left(T_{s}-T_{f}\right)=\frac{\partial T_{f}}{\partial t}+U \frac{\partial T_{f}}{\partial z} \\
h S_{s}\left(T_{s}-T_{f}\right)=-\rho_{s} C_{s}(1-\varepsilon) \pi R^{2} \frac{\partial T_{s}}{\partial t}
\end{gathered}
$$

where $h$ is the heat transfer coefficient between the capsules and the HTF, $S_{s}$ is defined as the heat transfer surface area of capsules per unit length of the storage tank, $\varepsilon$ is the porosity of the packed bed, $U$ is the flow velocity the HTF passes through the packed bed, $\mathrm{R}$ is the radius of the storage tank. Based on the Colburn factor relation[140], the heat transfer coefficient in a packed-bed thermal storage system can be found from reference[141]: $h=0.191 \dot{m} \operatorname{Re}^{-0.278} C_{f} \operatorname{Pr}_{f}^{-2 / 3} /\left(\varepsilon \pi R^{2}\right)$, where $\operatorname{Re}=2 r \cdot \dot{m} /(1-\varepsilon) \rho_{f} v_{f} \pi R^{2}, \operatorname{Pr}_{f}=v_{f} \rho_{f} C_{f} / k_{f}, \dot{m}$ is the mass flow rate, $R$ is the radius of the storage tank, $\varepsilon$ is the porosity of the packed system.

When a location is experiencing melting process, the energy equations of the HTF and the PCM becomes [142]:

$$
\begin{gathered}
\frac{h S_{s}}{\rho_{f} C_{f} \varepsilon \pi R^{2}}\left(T_{m}-T_{f}\right)=\frac{\partial T_{f}}{\partial t}+U \frac{\partial T_{f}}{\partial z} \\
h S_{s}\left(T_{m}-T_{f}\right)=-\Gamma \rho_{s}(1-\varepsilon) \pi R^{2} \frac{d \Phi}{d t}
\end{gathered}
$$

where the melting point is known as $T_{m}$, latent heat of the melting is $\Gamma$, and the percentage of melting 
1 is $\Phi$ (with melting starting point as $\Phi=0$ and melting completion point as $\Phi=1$ ).

A more generalenthalpy-based 1D transient model was proposed by Tumilowicz et al. [143] through introducing enthalpy of the PCM capsules. The governing equations include Eq. (3) and the following enthalpy equation for the capsules:

$$
\frac{\partial \bar{h}_{s}}{\partial t}=\frac{-h S_{s}\left(T_{s}-T_{f}\right)}{\rho_{s}(1-\varepsilon) \pi R^{2}}(7)
$$

The relationship between the enthalpy and the temperature of the capsules is defined by the equation of state as follows:

$$
T_{s}= \begin{cases}\frac{\left(\bar{h}_{s}-\bar{h}_{s_{-} r e f}\right)}{C_{s_{-}}}+T_{s_{-} r e f} & \bar{h}_{s}<\bar{h}_{s_{-} \text {melt }} \\ T_{s_{-} m e l t} & \text { for } \quad \bar{h}_{s_{-} \text {melt }} \leq \bar{h}_{s} \leq h_{s_{-} \text {melt }}+\Gamma(8) \\ \frac{\left(\bar{h}_{s}-\left(\bar{h}_{s_{-} \text {melt }}+\Gamma\right)\right)}{C_{s_{-} l}}+T_{s_{-} \text {melt }} & \bar{h}_{s_{-} \text {melt }}+\Gamma<\bar{h}_{s}\end{cases}
$$

The solution to the above equations only needs initial temperature conditions of fluid and solid in the tank and the time-dependent inlet fluid temperature.

Approaches of analytical solution assisted with numerical computation to the above equations have been well described in the work of Van Lew et al. [144] for thermal storage with no melting, and the work of Tumilowicz et al. [143] for the case with melting process.

The above mathematical modeling was developed referring to the configuration of HTF flowing through a packed bed of spherical capsules of PCM. This methodology of modeling can be easily extended to the cases that the PCM is encapsulated into a plate, a cylinder, or a cylindrical shell, as shown in Fig. 16, if an equivalent porosity is introduced by counting the volume of HTF and the total volume of the storage tank. 

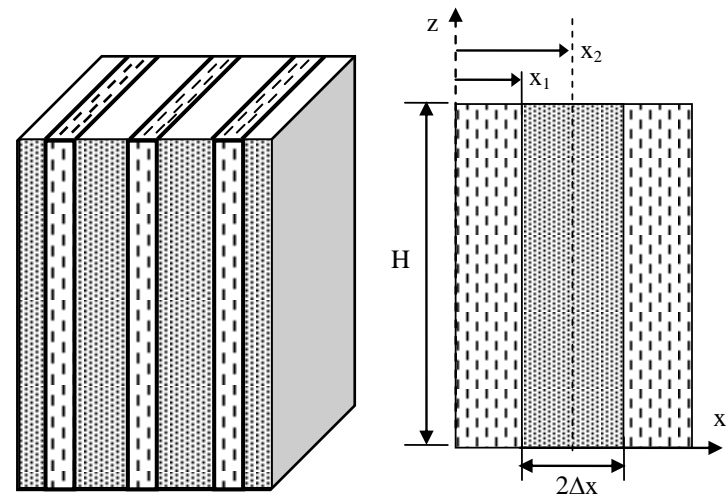

(a) Packed solid flat plates with HTF passing through the channels in a tank

3
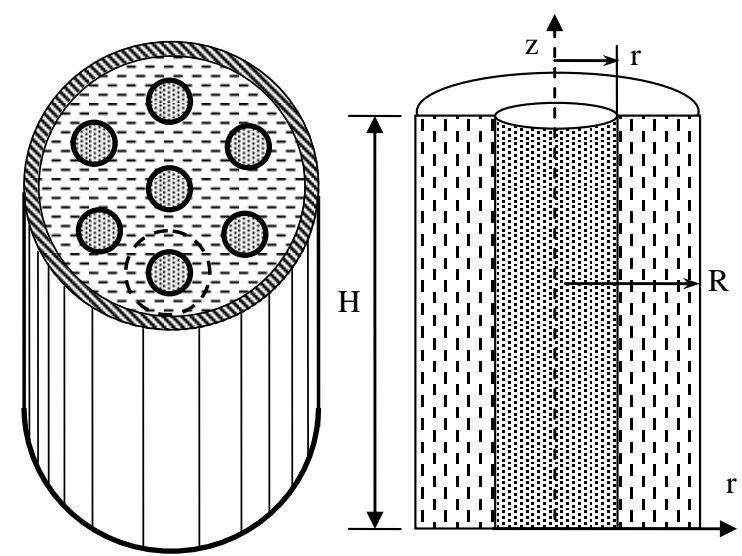

(b) Packed solid cylinders with HTF passing along in a tank

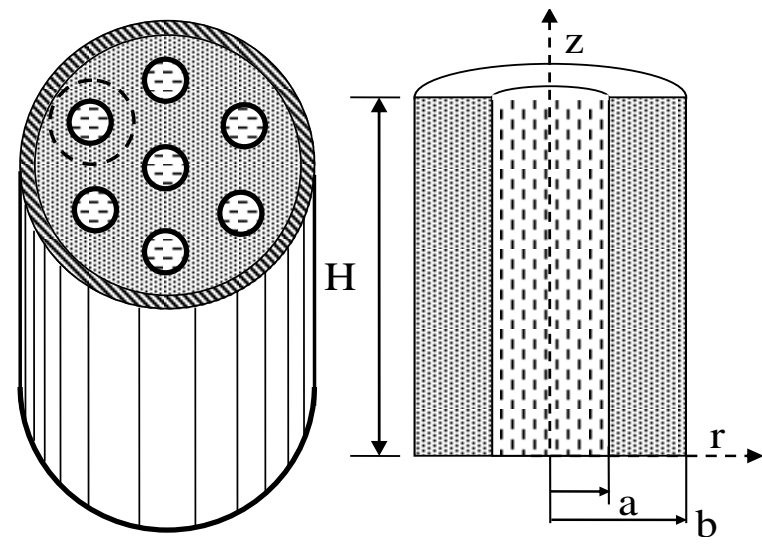

(c) Solid thermal storage material with HTF tubes passing through in a tank

Fig. 16Three other typical solid-fluid configuration in thermal storage systems

(1)

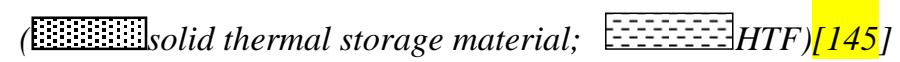

If the thermal conductivity in capsules and the convective heat transfer coefficient between capsules and the HTF cannot satisfy the requirement of Biot number less than 0.1 , as required in the assumption (4) for the one-dimensional mathematical modeling, a modified heat transfer coefficient 
1 will be introduced to replace $h$ in the governing equations (1) to (5). Expressions of the modified heat

2 transfer coefficient $h_{\text {eff }}$ for spherical capsules, and the three types of capsules in Fig. 12 are available

3 in the work by $\mathrm{Xu}$ et al. [146].

4 One-dimensional modeling has been the major tool mostly used to predict thermal storage

5 involving melting and solidification processes for packed-bed PCMTES system.A summary of recent

6 studies using one-dimensional modeling is given in Table 8.

7

8 Table 8Studies that used one-dimensionalnumerical model for spherical capsules ofPCMsinlatent heat

$9 \quad$ storage systems

\begin{tabular}{|c|c|c|}
\hline Reference & Model description & Numerical approach \\
\hline [147] 2001 & 1D model for LHTES systems with encapsulated PCMs & Integral method. \\
\hline$[148] 2002$ & $\begin{array}{l}\text { A simplified } 1 \mathrm{D} \text { model. Storage tank has a numbers of layers of } \\
\text { packaging. Convection in liquid phase of PCM was treated by } \\
\text { using an effective thermal conductivity. }\end{array}$ & $\begin{array}{l}\text { A marching technique in which the phase change } \\
\text { problem inside the spherical capsule is coupled } \\
\text { with the energy balance equation between the } \\
\text { spherical boundary and the working fluid. }\end{array}$ \\
\hline [84] 2009 & $\begin{array}{l}\text { 1D model usingequations similar to those of Schumann. } \\
\text { Enthalpy equation was used for phase change of PCM inside the } \\
\text { capsules. }\end{array}$ & Explicit, first order finite difference method. \\
\hline [143] 2014 & $\begin{array}{l}\text { Enthalpy-based } 1 \mathrm{D} \text { model was developed to track the solid-fluid } \\
\text { interface. Lumped capacitance method was applied using an } \\
\text { effective heat transfer coefficient to consider the internal heat } \\
\text { conduction of capsules. }\end{array}$ & Method of characteristics, explicit, trapezoidal rule. \\
\hline$[153] 2014$ & $\begin{array}{l}\text { 1D model. Used temperature-dependent correlations to obtain } \\
\text { the thermophysical properties for the HTF and considered heat } \\
\text { loss through the tank wall. }\end{array}$ & $\begin{array}{l}\text { Implicit finite volume method. Upwind scheme for } \\
\text { convective terms. }\end{array}$ \\
\hline
\end{tabular}
transfer between PCM package and HTF may also be analyzed using two-dimensional or three dimensional modeling. These models may treat the entire thermal storage container as a zone of porous media that HTF flows through, or may treat PCM zone and HTF zone with reasonable details and load 
1 of computations using comprehensive 3D CFD study. References that used two-dimensional and

2 three-dimensional modeling for the analysis of the heat transfer and energy storage are summarized in

3 Table 9 and Table 10.

4

5 Table 9Two-dimensionalthermocline modelling work forLHTES

\begin{tabular}{|c|c|c|}
\hline Reference & Model description & Numerical approach \\
\hline$[154] 2005$ & $\begin{array}{l}\text { A mathematical model of transient heat transfer in a } \\
\text { shell-and-tube latent thermal energy storage unit, with a } \\
\text { developed algorithm for non-isothermal phase transition }\end{array}$ & $\begin{array}{l}\text { Finite difference method, velocity and pressure fields of } \\
\text { HTF using SIMPLER algorithm, convection-diffusion } \\
\text { terms treated by the power-law scheme. }\end{array}$ \\
\hline$[155] 2005$ & $\begin{array}{l}\text { A numerical model for packed flat plate TES system, and } \\
\text { graphite matrix embedded with the PCM to enhance heat } \\
\text { transfer }\end{array}$ & Finite difference method, implicit scheme. \\
\hline$[156] 2005$ & $\begin{array}{l}\text { A comprehensive } 2 \mathrm{D} \text { porous-medium transient model for cold } \\
\text { storage with coolant flowing in a packed-bed encapsulated PCM } \\
\text { thermal storage system }\end{array}$ & $\begin{array}{l}\text { Implicit finite difference method, second order central } \\
\text { difference scheme for diffusion term, and Power law } \\
\text { scheme for convective terms, SIMPLEC for } \\
\text { velocity-pressure coupling. }\end{array}$ \\
\hline [104] 2006 & $\begin{array}{l}\text { The heat transfer characteristics of the melting process inside a } \\
\text { horizontal cylindrical capsule for paraffin wax PCM have been } \\
\text { investigated numerically. }\end{array}$ & $\begin{array}{l}\text { Finite difference approach and a fixed grid scheme } \\
\text { based on the technique of enthalpy method }\end{array}$ \\
\hline [157] 2009 & $\begin{array}{l}\text { Transient numerical model of shell-and-tube latent thermal } \\
\text { storage system with natural convection }\end{array}$ & $\begin{array}{l}\text { Implicit finite difference method, a uniform size and } \\
\text { constant time steps. }\end{array}$ \\
\hline$[158] 2010$ & $\begin{array}{l}\text { A comprehensive numerical } 2 \mathrm{D} \text { model for melting with natural } \\
\text { convection in a square cavity, the energy balance associated } \\
\text { with the phase change is represented by the temperature } \\
\text { transforming model. }\end{array}$ & $\begin{array}{l}\text { Implicit finite volume method, the consistent update } \\
\text { technique (CUT) algorithm was applied to couple } \\
\text { velocity-pressure, the central difference scheme for both } \\
\text { the convection and diffusion terms. }\end{array}$ \\
\hline [159] 2014 & $\begin{array}{l}\text { A comprehensive transient } 2 \mathrm{D} \text { model for charge/discharge } \\
\text { cycles by considering the natural convection. The temperature } \\
\text { variation in the tank is axisymmetric, and the temperature varies } \\
\text { radially inside the encapsulated PCM. }\end{array}$ & $\begin{array}{l}\text { An implicit method, with the convective-diffusive } \\
\text { fluxes in the HTF governing equation discretized using } \\
\text { the power-law scheme, and the diffusive fluxes in PCM } \\
\text { governing equation discretized using central } \\
\text { differencing scheme. }\end{array}$ \\
\hline$[160] 2015$ & $\begin{array}{l}\text { A Comprehensive transient and two-dimensional numerical } \\
\text { model with porous medium } \\
\text { (Note: the packed bed with spherical PCM is assumed to be a } \\
\text { continuous and homogeneous porous medium.) }\end{array}$ & $\begin{array}{l}\text { ANSYS Fluent } 13.0 \text { was applied, pressure based solver, } \\
\text { SIMPLE pressure-velocity coupling scheme, second } \\
\text { order upwind scheme. }\end{array}$ \\
\hline
\end{tabular}

6

7 Table 10Works using three-dimensionalthermocline modeling forLHTES systems

\begin{tabular}{|l|l|l|}
\hline Reference & Model description & Numerical approach \\
\hline$[161] 2007$ & $\begin{array}{l}\text { A 3D transient CFD model;the interpolating cubic spline } \\
\text { function method was used to determine the specific heat in each } \\
\text { time step of the temperature calculations. }\end{array}$ & $\begin{array}{l}\text { Implicit finite difference method, the standard Gauss } \\
\text { elimination method was used to solve the system of } \\
\text { equations. }\end{array}$ \\
\hline
\end{tabular}




\begin{tabular}{|l|l|l|}
\hline & $\begin{array}{l}\text { (Note: it is a packed flat plate storage system in a thermal } \\
\text { insulated ventilation duct.) }\end{array}$ & \\
\hline [162] 2009 & $\begin{array}{l}\text { A comprehensive 3D numerical simulation, 3 separated groups } \\
\text { of governing equations, for the PCM, the shell, and the HTF, } \\
\text { with thermodynamic analysis, first law and second law } \\
\text { efficiency. } \\
\text { (Note: it is a single spherical PCM capsule surrounded by the } \\
\text { heat transfer fluid.) }\end{array}$ & $\begin{array}{l}\text { ANSYS Fluent 6.3 was used, pressure based solver, and } \\
\text { the enthalpy-porosity method was applied to track the } \\
\text { solid-liquid interface. }\end{array}$ \\
\hline
\end{tabular}

1

2

3

4

It is worth noting that all the numerical models listed in Table 8-10 have been validated, and they all have good agreements with experimental data. As a result, these numerical models are encouraged to be applied in thermal storage applications if PCMs are adopted as storage materials.

Unlike the one-dimensional model, the lateral-direction heat conduction of the HTF and PCMisnot neglected in the two-dimensional and three-dimensional model. As a result, the axisymmetric or symmetric model with comprehensive simulation was commonly employed in two-dimensional model, without assuming fully developed flow condition. Due to the complexity of numerically simulating theflow and heat transfer in porous mediums (storage tank filled with encapsulated PCMs), there are onlya couple of research papers investigated the energy delivery and extraction using comprehensive 3DCFD study.Zukowski [161] performed a 3D comprehensive simulation for latent storage system incorporated with cubic encapsulated PCM using an in-house code, and the interpolating cubic spline function method was applied to determine the value of specific heat capacity of PCM in each time step, which can automatically track the melting and solidification of PCM capsules. MacPhee and Dincer [162] presented what appears to be the first CFD analysis for spherical encapsulated PCM inside a latent thermal storage tank. ANSYS Fluent 6.3 was applied with a pressure-based solver, and the enthalpy-porosity method was utilized to track the solid-liquid interface. More comprehensive three-dimensional CFD studies are expected in the future. For example, if the temperature difference between the surface of PCM and the inner wall of container is significant, the radiation heat transfer inside each PCM capsule cannot be neglected. As discussed before, by using the same effective heat transfer coefficient, the radiation heat transfer can also be included and accurately simulated. The reason for applying constant thermal-physical properties of PCM is to simplify and reduce the computational loads. Also indeed, the variation of the properties in a narrow temperature range of 150 ${ }^{\circ} \mathrm{C}$ is not significant. Among many thermal-physical properties of PCM, density, specific heat capacity 
and thermal conductivity are three most important properties. Temperature dependent properties will provide more accurate simulation results for a LHTES system.

It is important to note that the natural convection of the liquid phase PCM is an important factor to the heat transfer in PCM. At the beginning of the melting process, conduction is the dominant energy transfer mode. The importance of natural convection gradually increases as the melted region growsand the liquid-solid interface curves, thus augmenting the melting process. Rayleigh number (Ra), $R a=g \beta\left(T_{P}-T\right) L_{\infty}^{3} /(v \alpha)$ is a key dimensionless parameter to determine the onset of natural convection, where $g$ is the local gravitational acceleration; $\beta$ is the thermal expansion coefficient of liquid phase PCM; $T_{P}$ is the external surface temperature of PCM capsules; $L_{\infty}$ is the characteristic length-scale of convection, and usually it will be chosen as the thickness of liquid layer; $v$ is the kinematic viscosity of liquid phase PCM; $\alpha$ is the thermal diffusivity of liquid phase PCM.

In the works listed in Table 9 and 10, Kousksou et al. [156] did not consider natural convection in PCM capsule during phase change heat transfer processes. However, differentfrom the approach used by Kousksou et al.,Felix Regin et al. [104] considered the conduction inside PCM capsules as the dominant energy transfer mode, and used an equivalent thermal conductivity to merge the natural convection effect in the thermal conductivity of the liquid by using a relation:

$$
\bar{k}_{\text {eq_liquid }}=\bar{k}_{\text {eq }} \cdot k_{\text {liquid }}
$$

where the overall equivalent conductivity $\bar{k}_{e q}$ was defined as the ratio of total heat transfer rate to heat transfer rate by conduction $\left(\bar{k}_{e q}=N u / N u_{\text {conduction }}\right)$, and $k_{\text {liquid }}$ is the thermal conductivity of liquid $\mathrm{PCM}$, and $\bar{k}_{\text {eq_liquid }}$ is the mean equivalent thermal conductivity that merges natural convection.

Adine \& El Qarnia [157] and Zukowski [161] also processed the effects of natural convection during melting process by using an effective thermal conductivity of the liquid phase of the PCM. The thermal conductivity of the PCM is given by the following expression:

$$
k_{p}=f_{l} k_{e}+\left(1-f_{l}\right) k_{s}
$$

where $f_{l}$ is the liquid fraction, $k_{s}$ is the thermal conductivity of PCM in solid phase, and $k_{e}$ is the effective thermal conductivity of the liquid phase PCM, which takes into account the effect of 
natural convection on the heat transfer during melting. The expression of $k_{e}$ is giving by the following correlation:

$$
k_{e}=C k_{l} R a^{n}\left(\frac{\delta}{l}\right)^{m}
$$

where $k_{l}$ is the thermal conductivity of PCM in liquid phase, $R a$ is the Rayleigh number, $C$ is a constant of $0.05, n$ is a constant of $0.25, \delta$ is the PCM liquid thickness, $l$ is the PCM thickness, and $m$ is also a constant of 1.0 .

Wang et al. [158] considered the effects of natural convection inside a 2D square cavity filled with PCM, and the modeling of melting was simplified by considering melting as a process occurring within an artificial mushy zone associated with a finite temperature range from $-\delta \theta$ to $\delta \theta$, so that the latent heat was formally considered by a finite thermal capacity and source term.

Nithyanandam et al. [159] modeled the circulation of liquid due to buoyancy-driven natural convection currents during the melting of PCM using an enhanced effective thermal conductivity of the PCM melt front, $k_{p, \text { eff }}$, evaluated using the empirical correlation in [163], which covers both the conduction and convection regimes and is expressed as $k_{p, \text { eff }}=k_{p} \cdot N u_{\text {conv }}$, where $k_{p}$ is the molecular thermal conductivity of PCM and $N u_{\text {conv }}$ is calculated using [163]:

$$
N u_{\text {conv }}=1.16 f(\operatorname{Pr})\left(\frac{D_{o}-D_{i}}{2 D_{i}}\right)^{1 / 4} \frac{R a^{1 / 4}}{\left(D_{i} / D_{o}\right)^{3 / 5}+\left(D_{o} / D_{i}\right)^{4 / 5}}
$$

where $f(\operatorname{Pr})=\frac{2.012}{3}\left[1+\left(\frac{0.492}{\operatorname{Pr}}\right)^{9 / 16}\right]^{-4 / 9}$.

The correlation shown in Eq. (12) is valid for a wide range of Prandtl ( $\mathrm{Pr}$ ) number and Rayleigh number ( $R a$ ) of the PCM. The term $D_{o}-D_{i}$ in Eq. (12) represents the thickness of the liquid layer formed during melting of PCM. As we discussed before, since the thickness of the liquid layer is very small initially, heat transfer across the liquid layer occurs primarily by conduction although, ultimately, convection becomes important as the melt region expands. Therefore, heat transfer through the melting is calculated by evaluating a conduction heat transfer using $k_{p}$ and an overall thermal conductivity 
1 associated with the use of $k_{p, e f f}$ for considering free convection in a spherical enclosure. The

2 expression that yields the largest heat transfer rate was used in the computations in Ref. [159].

3

4 5. Integration and seamless operation of CSP using thermocline LHTES system

From a practical point of view, one way to have a good picture ofthermocline system behavior is

6 to simulate the annual performanceof a CSP plant.Several numerical models for parabolic trough CSP

7 plant that includethermal storage system have been developed by different organizations [164-168].All

8 these models only consider the conventional molten-salt two-tank storage system for which

9 outlet/inlettemperatures are fixed. However, in a thermocline storage tank, the available thermal energy

10 at maximum temperature is expected to decrease with subsequent charging/discharging cycles [169]

11 due to a continuous increase ofthermocline thickness. Moreover, thermocline thickness also increases during idle periods because of thermal diffusion [170], which decreases TES exergy and the potential attained. useful powerthat can be extracted.Bayón and Rojas [171] illustrated the difference between both two-tank andthermocline sensible storage systems in terms of outlet temperature as afunction of time for the particular case of an initial discharge process, as shown in Fig. 17. While the two-tank system provides maximum constant storage liquid temperature, $T_{\max }$, during the whole discharging processuntil the end; liquid outlet temperature for a thermocline tank startsdecreasing after a certain time, $t_{\text {partial-charge }}$ down to the minimumtemperature, $T_{\min }$ when full discharge time, $t_{\text {full-charge }}$ is attained.

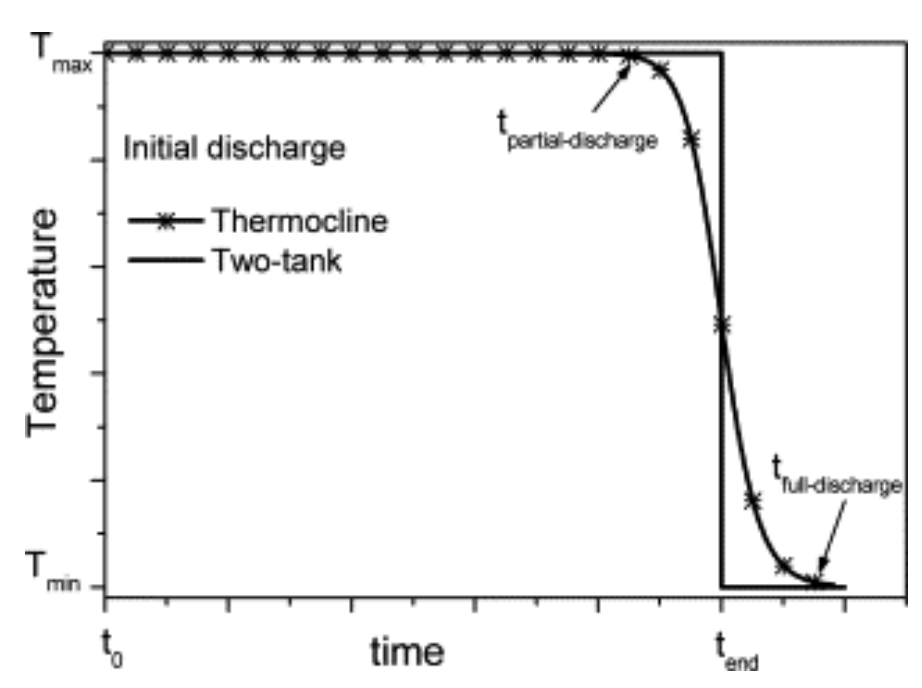


Fig. 17Outlet HTF temperature profile as a function of time for initial discharge processes corresponding to both a two-tank storage system and a single thermocline sensible heat storage tank.

[171]

Due to thermocline degradation, the annual electricity yield of a plant with thermocline storage is always lower than the same plant with a two-tank storage system. In this way, Biencinto et al. [172] carried out an annual performance analysis for different charge and discharge operation strategies, in order to find out the best operation mode that minimizes the difference in annual yield between both systems. With respect to the annual electricity yield, the best strategy for discharge processes is a total extraction of thermocline region, feeding the power block, firstly, for electricity production and, secondly, for the next day preheating. This strategy is easy to implement in a parabolic trough CSP plant and does not require more fossil consumption than keeping the remaining energy inside the tank.

However, according to the basic temperature requirement of Rankine cycle, which is applied by most commercialized CSP plants for power generation, the HTF temperature at the exit of storage tank (herein called as output HTF temperature) needs to be maintained above a cutoff temperature during the entire time period of discharge, below which HTF will not able to be used in the power cycle for electricity generation. In the past decade, several research works have been presented for the analysis of output HTF temperature of latent thermocline storage system.

Zanganeh et al. [173] presented a new TES configuration tostabilize the outflow temperature of a thermocline storage system incorporated withrocks and latent heat storage by adding a relatively small amount of PCM to the top of the packed-bed. In their numerical analysis, three different PCMs were adopted (PCM \#1: 27NaF-73NaBr, PCM \#2: 46LiF-44NaF-10MgF 2 , PCM \#3: 52LiF-35NaF-13CaF 2 ). Fig. 18 shows theoutflow HTF temperature as a function of time during discharging ofthe 9th cycle for three PCM packing heighton top of the packed-bed ofrocks (indicated as "Rocks + Material \#"). Also shown is the solid curvefor the packed bed of rocks without PCM (indicated as "Rocksonly"). It was reported by Zanganeh et al [173]that the outflow temperature during discharging can be kept constant around the PCM melting temperature by adopting PCM \#2 and PCM \#3, thereby eliminating the inherent temperature drop of TES based on sensible heat storage only. A PCM volume of only $1.33 \%$ of 
1

the total storage volume is sufficient to accomplish stabilization, corresponding to $4.4 \%$ of the total energy stored as latent heat.

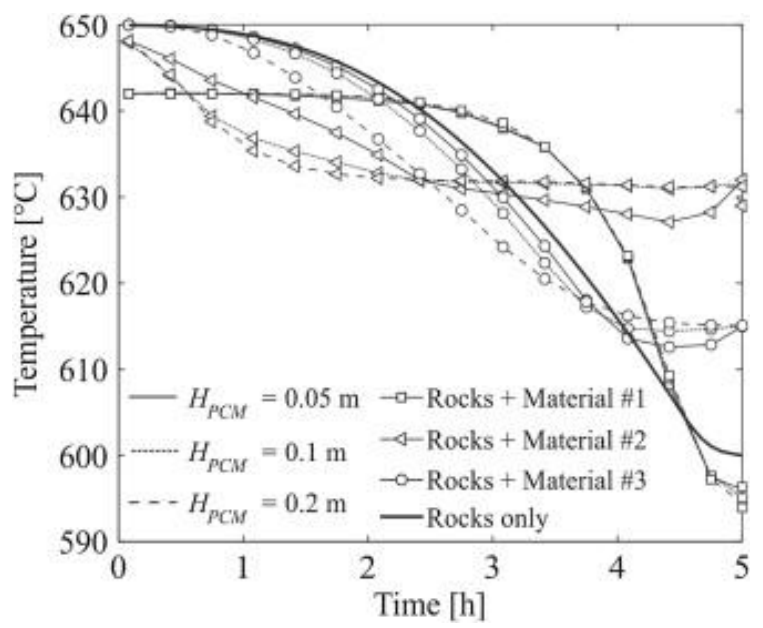

Fig. 18 Outflow air temperature as a function of time during discharging of the 9th cycle for various PCM's packing heights on top of the packed bed of rocks ("Rocks + Material \#”), and for the packed bed of rocks without PCM ("Rocks only"). [173]

Wu et al. [150] studied the dynamic characteristics of TES system with spherical capsules packed bed during discharging process using a one-dimensional model. Paraffin was taken as phase change material and water was used as heat transfer fluid. There are three stages during the discharging process, namely, liquid cooling, solidification (liquid-solid phase change) and solid cooling, as shown inFig. 19. It was observed that the temperature of PCM decreases rapidly until it reaches the solidification temperature. During the solidification process, the temperature of PCM remains uniform at the solidification temperature. Then, it decreases gradually to the inlet temperature of HTF at solid cooling stage. The time for total solidification at the middle location is about $160 \mathrm{~min}$ and at the outlet location is about $280 \mathrm{~min}$. This is due to the fact that heat transfer decreases as the temperature difference between PCM and HTF decreases along the direction of HTF flow. So, it is clear that the closer to the outlet location, the longer time for complete solidification and discharging process. 


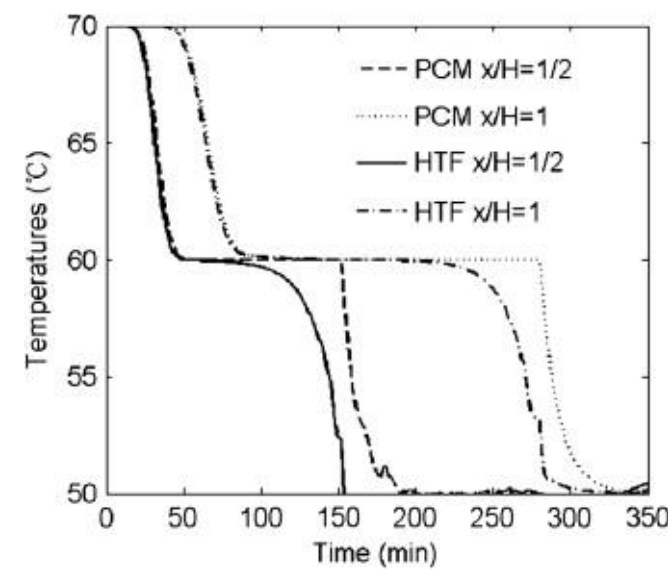

Fig. 19Temperature evolution of PCM and HTF for different locations. [150]

Unfortunately, Wu et al. [150] didn't pay attention to the cutoff temperature. In order to explorer the relationship between the melting temperature of PCM and the cutoff temperature, the current authors performed numerical investigation, using a 1D enthalpy-based transient model [143] and the general volume sizing strategy [138]. In thisanalysis, two different PCMs were adopted (PCM-1: KOH; PCM-2: NaCl-KCl, $58-42 \mathrm{wt} \%$ ), and the cutoff temperature was chosen as $360^{\circ} \mathrm{C}$, which was the same as the melting temperature of PCM-2. Following the general volume sizing strategy, with a fixed storage tank diameter of $10 \mathrm{~m}$ and a constant discharge time of 6 hours, it was found that PCM-1 can offer a storage tank height of $50.4 \mathrm{~m}$, while PCM- 2 can provide $43.7 \mathrm{~m}$ high of storage tank, and the outflow HTF temperature variation with discharge time is shown in Fig. 20, where the red dashed line indicates the cutoff temperature of $360^{\circ} \mathrm{C}$.

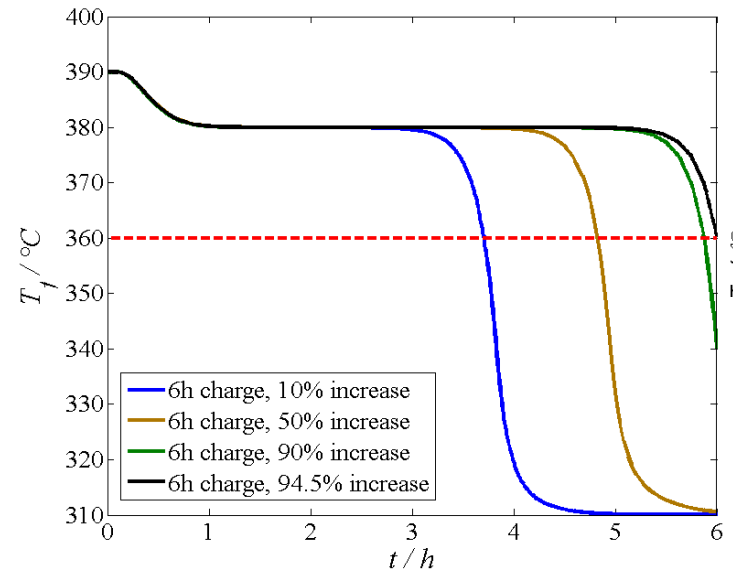

(a) PCM-1: $\mathrm{KOH}$

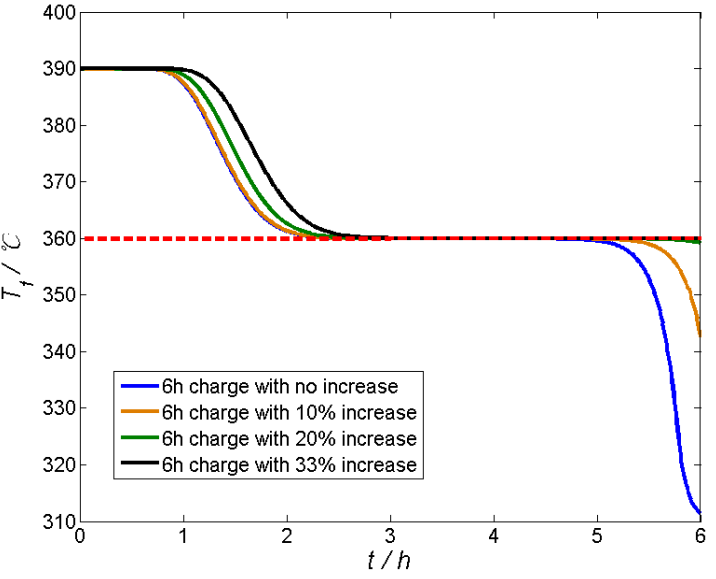

(b) PCM-2: NaCl-KCl, $58-42 \mathrm{wt} \%$ 
Table 11Commodity prices for selected PCMs investigations will be presented in the near future.

\section{Cost analysis for thermocline LHTES system}

\subsection{Cost of selected PCMs}

$$
\text { following the general volume sizing strategy }
$$

As a consequence, if the cutoff temperature can be kept the same as the melting temperature of PCM, such a phase change material can offer a smaller storage tank volume, which will lead to a significant reduction of material and construction cost. With the provided many thermophysical parameters of latent-heat thermocline TES system, a parametric study is necessary, and more

On the basis of the data collected by Kenisarin in 2010 [174], the current authors searched the updated commodity prices of some commonly used industrial grade PCMs for CSP application, and most of the prices were quoted from suppliers up-to-date in June 2015, which are listed in Table 11. It is seen that lithium carbonate is the most expensive salt, followed by aluminum fluoride and potassium hydroxide; while sodium fluoride and sodium chloride have the lowest prices.

\begin{tabular}{|l|c|l|c|}
\hline PCM & Price, \$/kg & PCM & Price, \$/kg \\
\hline $\mathrm{NaF}$ & $0.05[175]$ & $\mathrm{NaNO}_{3}$ & $0.38[176]$ \\
\hline $\mathrm{KF}$ & $0.10[177]$ & $\mathrm{KNO}_{3}$ & $0.85[178]$ \\
\hline $\mathrm{MgF}_{2}$ & $0.01[179]$ & $\mathrm{Ca}\left(\mathrm{NO}_{3}\right)_{2}$ & $0.25[180]$ \\
\hline $\mathrm{CaF}_{2}$ & $0.50[181]$ & $\mathrm{NaCl}$ & $0.05[182]$ \\
\hline $\mathrm{AlF}_{3}$ & $1.20[183]$ & $\mathrm{KCl}$ & $0.27[184]$ \\
\hline $\mathrm{Na}_{2} \mathrm{CO}_{3}$ & $0.18[185]$ & $\mathrm{MgCl}_{2}$ & $0.35[186]$ \\
\hline $\mathrm{Li}_{2} \mathrm{CO}_{3}$ & $5.71[187]$ & $\mathrm{BaCl}_{2}$ & $0.41[188]$ \\
\hline $\mathrm{K}_{2} \mathrm{CO}_{3}$ & $1.00[189]$ & $\mathrm{CaCl}_{2}$ & $0.14[190]$ \\
\hline $\mathrm{Na}_{2} \mathrm{CO}_{3}$ & $0.10[191]$ & $\mathrm{SrCl}_{2}$ & $0.80[192]$ \\
\hline $\mathrm{KOH}$ & $1.09[193]$ & $\mathrm{ZnCl}_{2}$ & $0.98[194]$ \\
\hline
\end{tabular}

19

Table 12Estimated prices for various salt mixtures*

\begin{tabular}{|l|c|l|c|}
\hline PCM $(\mathrm{wt} \%)$ & Price, $\$ \mathbf{k g}$ & $\mathbf{P C M}(\mathrm{wt} \%)$ & Price, $\mathbf{\$} / \mathbf{k g}$ \\
\hline $42 \mathrm{Ca}\left(\mathrm{NO}_{3}\right)_{2}-15 \mathrm{NaNO}_{3}-43 \mathrm{KNO}_{3}$ & 0.53 & $61 \mathrm{KCl}-39 \mathrm{MgCl}_{2}$ & 0.30 \\
\hline
\end{tabular}




\begin{tabular}{|c|c|c|c|}
\hline $54 \mathrm{KCl}-46 \mathrm{ZnCl}_{2}$ & 0.59 & $25 \mathrm{KCl}-27 \mathrm{CaCl}_{2}-48 \mathrm{MgCl}_{2}$ & 0.27 \\
\hline $48 \mathrm{NaCl}-52 \mathrm{MgCl}_{2}$ & 0.21 & $5 \mathrm{KCl}-29 \mathrm{NaCl}-66 \mathrm{CaCl}_{2}$ & 0.12 \\
\hline $32 \mathrm{KCl}-68 \mathrm{MgCl}_{2}$ & 0.32 & $28 \mathrm{KCl}-19 \mathrm{NaCl}-53 \mathrm{BaCl}_{2}$ & 0.31 \\
\hline $33 \mathrm{NaCl}-67 \mathrm{CaCl}_{2}$ & 0.11 & $24 \mathrm{KCl}-47 \mathrm{BaCl}_{2}-29 \mathrm{CaCl}_{2}$ & 0.30 \\
\hline $37 \mathrm{MgCl}_{2}-63 \mathrm{SrCl}_{2}$ & 0.63 & $32 \mathrm{Li}_{2} \mathrm{CO}_{3}-35 \mathrm{~K}_{2} \mathrm{CO}_{3}-33 \mathrm{Na}_{2} \mathrm{CO}_{3}$ & 2.21 \\
\hline $47 \mathrm{Li}_{2} \mathrm{CO}_{3}-53 \mathrm{~K}_{2} \mathrm{CO}_{3}$ & 3.21 & $40 \mathrm{KCl}-23 \mathrm{KF}-37 \mathrm{~K}_{2} \mathrm{CO}_{3}$ & 0.16 \\
\hline $44 \mathrm{Li}_{2} \mathrm{CO}_{3}-56 \mathrm{Na}_{2} \mathrm{CO}_{3}$ & 2.57 & $17 \mathrm{NaF}-21 \mathrm{KF}-62 \mathrm{~K}_{2} \mathrm{CO}_{3}$ & 0.65 \\
\hline $28 \mathrm{Li}_{2} \mathrm{CO}_{3}-72 \mathrm{~K}_{2} \mathrm{CO}_{3}$ & 2.32 & $35 \mathrm{Li}_{2} \mathrm{CO}_{3}-65 \mathrm{Na}_{2} \mathrm{CO}_{3}$ & 2.06 \\
\hline $51 \mathrm{~K}_{2} \mathrm{CO}_{3}-49 \mathrm{Na}_{2} \mathrm{CO}_{3}$ & 0.56 & $22 \mathrm{Li}_{2} \mathrm{CO}_{3}-16 \mathrm{Na}_{2} \mathrm{CO}_{3}-62 \mathrm{~K}_{2} \mathrm{CO}_{3}$ & 1.89 \\
\hline
\end{tabular}

Based on the prices in Table 11 for single specie/material, the prices of various mixturePCMs are calculated and given in Table 12. It is noted that the prices of the PCM may vary due to thevariation of market and supply situations.

The storage material cost is formulated as: $\left[\rho_{p}(1-\varepsilon) C_{p}^{*}+\rho_{f} \varepsilon C_{f}^{*}\right] \cdot \pi R_{t}^{2} H_{t}$ where $C_{p}^{*}$ is the PCM cost per unitmass, such astabulated in Table 12 , and $C_{f}^{*}$ is the HTF cost per unit mass. The cost of molten salt HTF in power tower CSP plant is around $\$ 1 / \mathrm{kg}[195,196]$. The cost of PCM encapsulation is usually measuredin terms of cost $/ \mathrm{kg}$ of capsule, and it alsoincreases with the increase of capsule radius due to higher cost of heat treatment and processing. Also, the stronger buoyancy driven natural convection that will be prevalent inside the molten PCM of larger capsules duringthe melting process requires a thicker shell material [197].

\subsection{Cost analysis of LHTES systems}

In 2011, the US Department of Energy launched the SunShot Initiative and hasput forth an aggressive R\&D (research and development) plan tomake CSP technologies cost-competitive with other energy generation sources on the grid by the end of the decade. The goal of the SunShot Initiative includes the LCOE (levelized cost of electricity) from solar power plants less than $6 \phi / \mathrm{kWh}$ without subsidies, a round-trip annualized exergetic efficiency greater than $95 \%$, storage cost less than $\$ 15 / \mathrm{kWht}$, by 2020 , which would pave way forrapid and large-scale adoption of solar electricity.

Pacheco et al. [198] presented what appears to be the first cost analysis of a sensible thermocline storage system.Considering an indirect configuration, temperature differential of $84^{\circ} \mathrm{C}, \mathrm{HTF}$ of 'solar salt', and storage medium of quartzite rocks, a cost of $\$ 13,900,000$ is calculated for a $688 \mathrm{MWh}$ system, 
corresponding to a capacity cost of $\$ 20 / \mathrm{kWh}$. EPRI [199] reported a much more thorough and detailed cost analysis procedure. Cost analysis of a molten salt thermocline storage system, ranging in capacity from $100 \mathrm{MWh}$ to $3500 \mathrm{MWh}$ was considered. It was reported that the capacity cost of a molten salt thermocline storage system ranges from $\$ 246 / \mathrm{kWh}$ to $\$ 34 / \mathrm{kWh}$ for the storage capacity ranging from $100 \mathrm{MWh}$ to $3500 \mathrm{MWh}$. Strasser and Selvam [200] performed cost analysis for utility-scale of 2165 MWh packed-bed and structured-concrete thermocline storage systems, indicating that a packed-bed thermocline TES system is $12.5 \%$ less costly than a structured-concrete thermocline TES $\operatorname{system}(\$ 30 / \mathrm{kWh}$ vs. $\$ 34 / \mathrm{kWh})$.

Relatively few works of cost analysis have been published for thermocline LHTESsystems.Nithyanandam and Pitchumani [133] presented a cost and performance analysis of concentrated solar power systems with integrated latent thermal energy storage, using a previously developed comprehensive transient 2D model [159]. In their analysis, two different types of latent thermal storage system, namelyEPCM-TES (encapsulated phase change material thermal energy storage) and HP-TES (latent thermal storage system with embedded Heat Pipes) systems were evaluated with respect to the storage capacity cost and annual exergetic efficiency. Based on their systematicparametric analysis on various performance metrics, feasibleoperating regimes and design conditions, it was found that the minimum LCOE obtained fromthe parametric study and the design window is at $5.37 \phi / \mathrm{kWh}$, less than theSunShot 2020 target of $6 \phi / \mathrm{kWh}$ for EPCM-TES system. Also, it was found that the maximum cost of heat pipesembedded in latent heat TES, which satisfies the SunShot requirements, is $\$ 4 /$ unit HP (heat pipe). The results provide first-hand information foroptimum operation and design of the latent thermal storagesystems for CSP plants.

Xu et al. [138] performed a simple cost analysis for the comparison between SHTES and LHTES, based on a previously developed 1D enthalpy-based transient model [143]. According to the general volume sizing strategy proposed by the authors[138,201], the storage media cost for four different systems (SHTES with granite rocks under $6 \mathrm{~h}$ charge, LHTES with KOH under $8 \mathrm{~h}$ charge, LHTES with $\mathrm{KOH}$ under $6 \mathrm{~h}$ charge, LHTES with $58 \% \mathrm{NaCl}-42 \% \mathrm{KCl}$ under $6 \mathrm{~h}$ charge) were calculated and compared, for a parabolic trough CSP plant with $60 \mathrm{MW}$ electrical power output at a thermal efficiency of 35\%. The authors [138] reported the capacity cost of three different LHTES systems, which are much higher than the capacity costs listed in Ref. [200], and this isbecause the cost of Therminol VP-1 
1 HTF is much higher thanthat of 'Solar Salts' HTF, for example the cost of Therminol VP-1 is $\$ 26.3 / \mathrm{kg}$,

2 while the cost of Solar Salt is only $\$ 0.5 / \mathrm{kg}$. Using the prices from several different distributors

3 mentioned by Strasser and Selvam [200], the cost analysis listed in Ref. [138] has been revised by

4 replacing Therminol VP-1 with Solar Salts, and the updated capacity cost for each system is shown in

5 Table 12.The results show that LHTES using salt $(58 \% \mathrm{NaCl}-42 \% \mathrm{KCl})$ with 6 hcharge has the lowest

6 capacity cost of $\$ 20.5 / \mathrm{kWh}$, which is about $43 \%$ less than that of SHTES using granite rock with $6 \mathrm{~h}$

7 charge. The capacity costs of LHTES of KOH with $8 \mathrm{~h}$ charge andLHTES of KOH with 6 h charge are

8 at the same level of $\$ 20.5 / \mathrm{kWh}$. Comparing the thermocline energy capacity costs, it is found

9 thatLHTES has at least 35\%, at most $43 \%$ reduction thanthat of SHTES. The capacity costs listed in

10 Table 12 are still higher than the targeted capacity cost of $\$ 15 / \mathrm{kWh}$ from DOE Sunshot program.

11 Systematic optimizations to LHTES and SHTES systems are needed to achieve the goal.

12

13 Table 12Capacity cost analysis of SHTES and LHTES

\begin{tabular}{|l|l|l|l|l|}
\hline Cost contributor & \multicolumn{4}{|l|}{ Thermocline storage system (60 MWe, 35\% thermal efficiency) } \\
\hline & $\begin{array}{l}\text { SHTES with granite } \\
\text { rocks under 6h charge }\end{array}$ & $\begin{array}{l}\text { LHTES with KOH } \\
\text { under 8h charge }\end{array}$ & $\begin{array}{l}\text { LHTES with KOH } \\
\text { under 6h charge }\end{array}$ & $\begin{array}{l}\text { LHTES with 58\% NaCl - } \\
42 \% \text { KCl under 6h charge }\end{array}$ \\
\hline Energy storage media & $\$ 155,072.65$ & $\$ 527,597.50$ & $\$ 566,965.75$ & $\$ 731,824.70$ \\
\hline Storage tank & $\$ 8,000,00$ & $\$ 4,000,00$ & $\$ 5,000,00$ & $\$ 3,000,00$ \\
\hline Foundation & $\$ 3,000,000$ & $\$ 3,000,000$ & $\$ 3,000,000$ & $\$ 3,000,000$ \\
\hline Platform and steel & $\$ 2,898,600$ & $\$ 1,449,300$ & $\$ 1,449,300$ & $\$ 1,449,300$ \\
\hline Insulation & $\$ 2,062,800$ & $\$ 1,062,800$ & $\$ 1,062,800$ & $\$ 1,062,800$ \\
\hline Pumps and PCE & $\$ 6,673,660$ & $\$ 6,673,660$ & $\$ 6,673,660$ & $\$ 6,673,660$ \\
\hline Piping and valves & $\$ 2,177,830$ & $\$ 2,177,830$ & $\$ 2,177,830$ & $\$ 2,177,830$ \\
\hline Electrical & $\$ 550,742$ & $\$ 550,742$ & $\$ 550,742$ & $\$ 550,742$ \\
\hline Instrument/controls & $\$ 322,118$ & $\$ 322,118$ & $\$ 322,118$ & $\$ 322,118$ \\
\hline Construction costs & $\$ 11,695,260$ & $\$ 4,847,630$ & $\$ 5,847,630$ & $\$ 3,847,630$ \\
\hline Constr. management & $\$ 1,500,000$ & $\$ 1,500,000$ & $\$ 1,500,000$ & $\$ 1,500,000$ \\
\hline Installed cost & $\$ 31,036,083$ & $\$ 22,111,678$ & $\$ 23,151,046$ & $\$ 21,315,905$ \\
\hline Capacity cost $(\$ / \mathrm{kWh})$ & $\$ 30.1$ & $\$ 20.5$ & $\$ 22.2$ & $\$ 20.8$ \\
\hline
\end{tabular}

14

In order to further analyze the levelized cost of electricity for LHTES system, according to the

16 LCE(Levelized cost of electricity) calculator on NREL website [202], a rudimentary LCE cost analysis

17 is provided in Table 13 for the four thermal storage systems listed in Table 12. In this cost analysis, a 
1 fixed discount rate of 3\%/year for system lifetimes of 25 years is assumed. The capacity factor is

2 assumed to be $60 \%$, and the cost of operation and maintenance is also assumed to be a constant of

$3 \$ 40 / \mathrm{kWe}-\mathrm{yr}$. Then based on the current electricity retail price and cost escalation rate in Southwest

4 region of US, the LCE for each system can be calculated, as shown in Table 13.

5

6 Table 13 Levelized Cost of Electricity for a 60MWe CSP plant for SHTES and LHTES

\begin{tabular}{|l|l|l|l|l|}
\hline Cost contributor & \multicolumn{4}{|l|}{ Thermocline storage system (60 MWe, 35\% thermal efficiency) } \\
\hline & $\begin{array}{l}\text { SHTES with granite } \\
\text { rocks under 6h charge }\end{array}$ & $\begin{array}{l}\text { LHTES with KOH } \\
\text { under 8h charge }\end{array}$ & $\begin{array}{l}\text { LHTES with KOH } \\
\text { under 6h charge }\end{array}$ & $\begin{array}{l}\text { LHTES with 58\% NaCl - } \\
42 \% \mathrm{KCl} \text { under 6h charge }\end{array}$ \\
\hline Periods (Years) & 25 & 25 & 25 & 25 \\
\hline Discount Rate & $3 \%$ & $3 \%$ & $3 \%$ & $3 \%$ \\
\hline Capital Cost $\$ / \mathrm{kW})$ & $\$ 517.30$ & $\$ 368.50$ & $\$ 385.90$ & $\$ 355.30$ \\
\hline Fixed O\&M cost, $/ \mathrm{kWe-yr}$ & $\$ 40$ & $\$ 40$ & $\$ 40$ & $\$ 40$ \\
\hline Variable O\&M Cost $(\$ / \mathrm{kWh})$ & 0.002 & 0.002 & $43.6 \%$ & 0.002 \\
\hline Capacity factor & $43.6 \%$ & $43.6 \%$ & 12 & $43.6 \%$ \\
\hline Electricity Price $(\mathrm{cents} / \mathrm{kWh})$ & 12 & 12 & $2.3 \%$ & 12 \\
\hline Cost Escalation Rate & $2.3 \%$ & $2.3 \%$ & 9.8 & $2.3 \%$ \\
\hline Levelized cost of electricity, $\phi / \mathrm{kWh}$ & 10.0 & 9.8 & 9.8 \\
\hline
\end{tabular}

7

8

9

12

As shown in Table 13, the levelized cost of electricity for SHTES is $0.2 \phi / \mathrm{kWh}$ higher than LHTES, and all three LHTES system almost have the same LCE, but all of them are higher than the targeted LCE of $6 \phi / \mathrm{kWh}$ from DOE SunShot program. Once again, it indicates the necessity of optimizing the thermal storage system before they are employed in practical applications.

\section{Concluding remarks and discussions}

The development of concentrated solar power systems has been focused on thermal performance, reliability, and cost,of the system with thermal energy storage, as evident from a large amount of research and publications through sustained, long-term support and investments by government agencies and industries worldwide.Thermal storage in the form of sensible heat, or latent heat, or a combination of both is considered in CSP industry. Studies conducted tocompare latent thermal storage and sensible heat storage have shown thata significant reduction of storage tank volume can be achieved usingPCMs.

This work surveys the state-of-the-art technologies of LHTES especially PCM encapsulation and 
thermocline heat transfer of packed PCM capsules. First, some commonly-used phase change materials were categorizedbased on the temperature ranges of application. A list of industrial manufacturers and companies possessing encapsulation technologies is provided. Giving considerations to the heat transfer enhancement approaches in latent heat storage system, details of numerical modeling of latent heat thermocline heat transfer is provided. The relationship between PCM melting temperature and the cutoff temperature (lowest HTF temperature acceptable by power plant) is discussed.Conclusions from literature showed that if the cutoff temperature can be kept the same as the melting temperature of a PCM, such a phase change material can offer a smaller storage tank volume, which will lead to a significant reduction of material and construction cost.At the end, studies about the cost of PCM-based thermal energy storage system is analyzed, by providing a list of prices of some phase change materials and a cost analysiscomparing SHTES and LHTES systems.

By developing and deploying more efficient CSP plants with TES systems, the sun's free and clean energy can be harnessed to power homes, businesses, and communities around the world. This will lead to reduction of harmful carbon pollution and keeping our global environment clean for the future generations. It is expected that this review is beneficial to the fast developing LHTES technologiesfor CSP industries.

\section{ACKNOWLEDGEMENTS}

The authors gratefully acknowledge the financial support for this work from Departmentof Energy (DOE) Grant No. DE-EE0005942. 


\section{REFERENCES}

[1] International Energy Agency (IEA)’s World Energy Outlook 2014; http://www.worldenergyoutlook.org

[2] Regin A. F., Solanki S.C., Saini J.S. Heat transfer characteristics of thermal energy storage system using PCM capsules: a review. Renewable and Sustainable Energy Reviews 2008; 12(9): 2438-2458.

[3] Py X., Azoumah Y., Olives R. Concentrated solar power: Current technologies, major innovative issues and applicability to West African countries. Renewable and Sustainable Energy Reviews 2013; 18: 306-315.

[4] Solar (PV and CSP). http://www.iea.org/topics/solarpvandcsp (accessed in November 2014).

[5] Dubey S., Sarvaiya J.N., Seshadri B. Temperature dependent photovoltaic (PV) efficiency and its effect on PV production in the world-A review. Energy Procedia 2013; 33: 311-321.

[6] Cooper C., Sovacool B.K. Miracle or mirage? The promise and peril of desert energy part 1. Renewable Energy 2013; 50: 628-636.

[7] Sun J., Liu Q., Hong H. Numerical study of parabolic-trough direct steam generation loop in recirculation mode: Characteristics, performance and general operation strategy. Energy Conversion and Management 2015; 96: 287-302.

[8] NREL (2015) Concentrating Solar Power Projects, National Renewable Energy Laboratory (NREL).

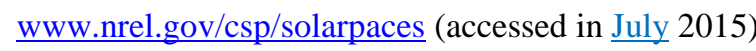

[9] Shouman ER, Khattab N.M. Future economic of concentrating solar power (CSP) for electricity generation in Egypt. Renewable and Sustainable Energy Reviews 2015; 41: 1119-1127.

[10] IRENA (2014) Renewable Energy Technologies: Cost Analysis Series, Concentrating solar power.

Vol 1. Power Sector Issue 2/5, June 2012

http://www.irena.org/documentdownloads/publications/re_technologies_cost_analysis-csp.pdf

[11]IEA (2010), Technology Roadmap: Concentrating Solar Power.

https://www.iea.org/publications/freepublications/publication/csp_roadmap.pdf

[12] Müller-Steinhagen H, Trieb F. Concentrating solar power: A review of the technology. Ingenia Inform QR Acad Eng 2004; 18: 43-50.

[13] Herrmann U, Kearney DW. Survey of thermal energy storage for parabolic trough power plants. ASME Journal of Solar Energy Engineering 2002; 124(2): 145-152. 
[14] Herrmann U, Kelly B, Price H. Two-tank molten salt storage for parabolic trough solar power plants. Energy 2004; 29(5-6): 883-893.

[15] Pacheco JE, Gilbert R. Overview of recent results of the solar two test and evaluations program, renewable and advanced energy systems for the 21st century. Proceedings of ASME International Solar Energy Conference. 1999.

[16] Pacio J, Wetzel T. Assessment of liquid metal technology status and research paths for their use as efficient heat transfer fluids in solar central receiver systems. Solar Energy 2013; 93: 11-22.

[17] Tian Y, Zhao CY. A review of solar collectors and thermal energy storage in solar thermal applications. Applied Energy 2013; 104: 538-553.

[18] Cordaro JG, Rubin NC, Bradshaw RW. Multicomponent Molten Salt Mixtures Based on Nitrate/Nitrite Anions. ASME Journal of Solar Energy Engineering 2011; 133: 011014.

[19] Bauer T, Laing D, Tamme R. Recent progress in alkali nitrate/nitrite developments for solar thermal power applications. Molten Salts Chemistry and Technology. Trondheim, Norway. June 2011. [20] Guillot S, Faik A, Rakhmatullin A, Lambert J, Veron E, Echegut P, Bessada C, Calvet N, Py X. Corrosion effects between molten salts and thermal storage material for concentrated solar power plants. Applied Energy 2012; 94: 174-181.

[21] Li PW, Chan CL, Hao Q, Deymier PA, Muralidharan K, Gervasio DF, Momayez M, Jeter S, Teja AS, Kannan AM. Halide and oxy-halide eutectic systems for high performance high temperature heat transfer fluids. SunShot Concentrating Solar Power Program Review. 2013.

[22] Kuravi S, Trahan J, Goswami DY, Rahman MM, Stefanakos EK. Thermal energy storage technologies and systems for concentrating solar power plants. Progress in Energy and Combustion Science $2013 ; 39(4): 285-319$.

[23] Abhat A. Low temperature latent heat thermal energy storage: heat storage materials. Solar Energy $1983 ; 30(4): 313-32$.

[24] Morrison D. J., Abdel-Khalik S. I. Effects of phase-change energy storage on theperformance of air-based and liquid-based solar heating systems. Solar Energy 1978; 20: 57-67.

[25] Ghoneim AA. Comparison of theoretical models of phase-change and sensibleheat storage for air and water-based solar heating systems. Solar Energy 1989; 42(3):209-20. 
[26] Tamme R, Laing D, Steinmann WD. Advanced thermal energy storage technology for parabolic trough. ASME Journal of Solar Energy Engineering 2004; 126(2): 794-800.

[27] Adinberg R., Zvegilsky D., Epstein M. Heat transfer efficient thermal energy storage for steam generation, Energy Conversion and Management 2010; 51: 9-15.

[28] Kenisarin M.M. High temperature phase change materials for thermal energy storage, Renewable and Sustainable Energy Reviews 2010; 14: 955-970.

[29] Zalba B., Marin J.M., Cabeza L.F., Mehling H. Review on thermal energy storage with phase change: materials, heat transfer analysis and applications, Applied Thermal Engineering 2003; 23 : $251-283$.

[30] Sharma A., Tyagi V.V., Chen C.R., Buddhi D. Review on thermal energy storage with phase change materials and applications, Renewable and Sustainable Energy Reviews 2009; 13: 318-345.

[31] Bradshaw R.W., Siegel N.P. Molten nitrate salt development for thermal energy storage in parabolic trough solar power systems, in: ES2008-54174 Proceedings of Energy Sustainability, August 2008.

[32] Sabharwall P., Patterson M., Utgikar V., Gunnerson F. NGNP process heat utilization: liquid metal phase change heat exchanger, in: Proceedings of the 4th International Topical Meeting on High Temperature Reactor Technology HTR, Washington DC, USA, 2008.

[33] Carberry J.J., Media for heat transport, Chemical Engineering 1953; 60(6): 225-228.

[34] Uhl V.W., Voznick H.P. Molten salt as a heat transfer medium, Chemical Engineering Progress $1963 ; 59(5): 33-35$.

[35] Sharma A., Tyagi V. V., Chen C. R., Buddhi D. Review on thermal energy storage with phase change materials and applications.Renewable and Sustainable energy reviews 2009; 13(2): 318-345.

[36] Hoshi A., Mills D.R., Bittar A., Saitoh T.S. Screening of high melting point phase change materials (PCM) in solar thermal concentrating technology based on CLFR, Solar Energy 2005; 79: $332-339$.

[37] Dincer I., Rosen M.A. Thermal energy storage, Systems and Applications, John Wiley \& Sons, Chichester (England), 2002.

[38] Lane G.A. Low temperature heat storage with phase change materials, International Journal of Ambient Energy 1980; 1: 155-168. 
[39] Bejan Adria. Entropy generation minimization: the method of thermodynamic optimization of finite-size systems and finite-time processes. CRC Press; 1996.

[40] Pincemin S, Olives R, Py X, Christ M. Highly conductive composites made of phase change materials and graphite for thermal storage. Solar Energy Materials \& Solar Cells 2008; 92: 603-13.

[41] Zalba B, Marı'n JM, Cabeza LF, Mehling H. Review on thermal energy storagewith phase change: materials, heat transfer analysis and applications. Applied Thermal Engineering 2003; 23(3): 251-283.

[42] Farkas D, Birchenall CE. New eutectic alloys and their heats of transformation. Metallurgical Transactions A 1985; 16A: 324-328.

[43] Dincer I., Rosen M.A. Thermal energy storage, Systems and Applications, John Wiley \& Sons, Chichester (England), 2002.

[44] Lane G.A. Low temperature heat storage with phase change materials, International Journal of Ambient Energy 1980; 1: 155-168.

[45] Marianowski LG, Maru HC. Latent heat thermal energy storage systems above $450^{\circ} \mathrm{C}$. In: Proceedings of 12 th intersociety energy conversion engineeringconference; 1977. p. 555-566.

[46] Maru HC, Dullea JF, Kardas A, Paul L, Marianowski LG, Ong E, et al. Molten salts energy storage systems. Chicago, IL: Final Report of the Institute of Gas Technology; 1978.

[47]Agyenim F., Hewitt N., Eames P., Smyth M. A review of materials, heat transfer and phase change problem formulation for latent heat thermal energy storage systems (LHTESS).Renewable and Sustainable Energy Reviews 2010;14(2): 615-628.

[48] Birchenall CE, Riechman AF. Heat storage in eutectic alloys. Metallurgical Transactions A 1980; 11A(8): 1415-1420.

[49] Gong Z, Mujumdar AS. Finite-element analysis of cyclic heat transfer in ashell and tube latent heat energy storage exchanger. Applied Thermal Engineering 1997; 17(4): 583-91.

[50] Pilkington Solar International, Survey of thermal storage for parabolic trough power plants, Report NREL1EC24 (2002).

[51] Liu, M., Gomez, J. C., Turchi, C. S., Tay, N. H. S., Saman, W., Bruno, F. Determination of thermo-physical properties and stability testing of high-temperature phase-change materials for CSP applications. Solar Energy Materials and Solar Cells 2015; 139: 81-87.

[52] Lane, G.A. Phase change materials for energy storage nucleation to prevent supercooling. Sol. 
Energy Mater. Sol. Cells 1992; 27: 135-160.

[53] Misra AK, Whittenberger JD. Fluoride salts and container materials for thermal energy storage applications in the temperature range 973 to $1400 \mathrm{~K}$. Proceedings of 22nd Intersociety Energy Conversion Engineering Conference 1987; AIAA-87-9226: 22.

[54] Gomez, J. C. High-temperature phase change materials (PCM) candidates for thermal energy storage (TES) applications. National Renewable Energy Laboratory 2011; NREL/TP-5500-51446.

[55] Qiu, S., Galbraith, R. Material Compatibility Study for Thermal Energy Storage Containment Structure With Phase Change Material. Proceedings of ASME 2013 International Mechanical Engineering Congress and Exposition. 2013, November, San Diego, CA.

[56] Available from www.pcmproducts.net; www.pcmproducts.net/files/PlusICE\%20Range-2013.pdf

[57] Horbaniuc B, Dumitrascua G, Popescub A. Mathematical models for the studyof solidification within a longitudinally finned heat pipe latent heat thermal storage system. Energy Conversion \& Management 1999; 40: 1765-74.

[58] Agyenim F, Eames P, Smyth M. A comparison of heat transfer enhancement ina medium temperature thermal energy storage heat exchanger using fins. Solar Energy 2009; 83(9): 1509-20.

[59] Papanicolaou E, Belessiontis V. Transient natural convection in a cylindricalenclosure at high Rayleigh numbers. Heat and Mass Transfer 2001; 45: 1425-44.

[60] Zivkovic B, Fujii I. An analysis of isothermal phase change material within rectangular and cylindrical containers. Solar Energy 2001; 70(1): 51-6.

[61] Silva PD, Goncalves LC, Pires L. Transient behaviour of a latent-heat thermalenergy store: numerical and experimental studies. Applied Energy 2002; 73: 83-98.

[62] Salunkhe P. B., Shembekar P. S. A review on effect of phase change material encapsulation on the thermal performance of a system. Renewable and Sustainable Energy Reviews 2012; 16(8): $5603-5616$.

[63] Verma P, Singal SK. Review of mathematical modeling on latent heat thermal energy storage systems using phase-change material. Renewable and Sustainable Energy Reviews 2008; 12(4): 999-1031.

[64] Abdel-Wahed RM, Ramsey JW, Sparrow EM. Photographic study of meltingabout an embedded horizontal heating cylinder. International Journal of Heat and Mass Transfer 1979; 22: 171-3. 
[65] Ermis K, Erek A, Dincer I. Heat transfer analysis of phase change process in afinned-tube thermal energy storage system using artificial neural network. International Journal of Heat and Mass Transfer 2007; 50: 3163-75.

[66] Ismail KAR, Alves CLF, Modesto MS. Numerical and experimental study on thesolidification of PCM around a vertical axially finned isothermal cylinder. Applied Thermal Engineering 2001; 21: $53-77$.

[67] Choi JC, Kim SD. Heat transfer characteristics of a latent heat storage system using MgCl2_6H2O. Energy 1992; 17(12): 1153-64.

[68] Agyenim F, Hewitt N, Eames P, Smyth M. Numerical and experimentaldevelopment of medium temperature thermal energy storage (Erythritol)system for the hot side of $\mathrm{LiBr} / \mathrm{H} 2 \mathrm{O}$ air conditioning applications. In: World Renewable Energy Congress 2008; 2008.

[69] Horbaniuc B, Dumitrascua G, Popescub A.Mathematical models for the studyof solidification within a longitudinally finned heat pipe latent heat thermal storage system. Energy Conversion \& Management 1999; 40: 1765-74.

[70] Sparrow EM, Larson ED, Ramsey JW. Freezing on a finned tube for eitherconduction-controlled or natural convection-controlled heat transfer. International Journal of Heat and Mass Transfer 1981; 24: $273-84$.

[71] Sasaguchi K, Takeo H. Effect of the orientation of a finned surface on the melting of frozen porous media. Heat and Mass Transfer 1994; 37(1): 13-26.

[72] Zhang Y, Faghri A. Heat transfer enhancement in latent heat thermal energystorage system by using the internally finned tube. International Journal of Heat Mass Transfer 1996; 39(15): 3165-73.

[73] Velraj R, Seeniraj RV, Hafner B, Faber C, Schwarzer K. Heat transfer enhancement in a latent heat storage system. Solar Energy 1999; 65(3): 171-180.

[74] Fukai J., Hamada Y., Morozumi Y., Miyatake O. Effect of carbon-fiber brushes on conductive heat transfer in phase change materials. International Journal of Heat and Mass Transfer 2002; 45(24): 4781-4792.

[75] Trelles JP, Dufly JJ. Numerical simulation of porous latent heat thermal energystorage for thermoelectric cooling. Applied Thermal Engineering 2003; 23: 1647-64.

[76] Hoogendoorn CJ, Bart GCJ. Performance and modelling of latent heat stores. Solar Energy 1992; 
48(1): 53-8.

[77] Sari A, Kaygusuz K. Thermal performance of myristic acid as a phase change material for energy storage, application. Renew Energy 2001; 24: 303-317.

[78] Mettawee ES, Assassa GMR. Thermal conductivity enhancement in a latent heat storage system. Solar Energy 2007; 81: 839-45.

[79] Griffiths PW, Eames PC. Performance of chilled ceiling panels using phasechange material slurries as the heat transport medium. Applied Thermal Engineering 2007; 27: 1756-60.

[80] Hawlader MNA, Uddin MS, Khin MM. Microencapsulated PCM thermalenergy storage system. Applied Energy 2003; 74: 195-202.

[81] Hendra R, Hamdani, Mahlia TMI, Masjuki HH. Thermal and melting heattransfer characteristics in a latent heat storage system using mikro. Applied Thermal Engineering 2005; 25: 1503-15.

[82] Agyenim F, Eames P, Smyth M. Heat transfer enhancement in mediumtemperature thermal energy storage system using a multitube heat transfer array. Renewable Energy 2010; 35(1): 198-207.

[83] Wu S, Fang G. Dynamic Discharging Characteristics Simulation on Solar Heat Storage System with Spherical Capsules using Paraffin as Heat Storage Material. Renew Energy 2011; 36: 1190-1195. [84] Regin AF, Solanki SC, Saini JS. An analysis of a packed bed latent heat thermal energy storage system using PCM capsules: Numerical investigation. Renew Energy 2009; 34(7): 1765-1773.

[85] Available from www.rubitherm.de

[86] Available from www.climator.com

[87] Khudhair AM, Farid MM. A review on energy conservation in building applications with thermal storage by latent heat using phase change materials. Energy Conversion and Management 2004; 45: $263-75$.

[88] Xi L, Zhang P, Wang RZ. Preparation and thermal characterization of expanded graphite/paraffin composite phase change material. Carbon 2010; 48: 2538-48.

[89] Cabeza LF, Castellon C, Nogues M, Medrano M. Use of microencapsulated PCM in concrete walls for energy savings. Energy and Buildings 2007; 39: 113-9.

[90] Fang G, Li H, Yang F, Liu X, Wu S. Preparation and characterization of nano-encapsulated n-tetradecane as phase change material for thermal energy storage. Chemical Engineering Journal 2009; 153: $217-21$ 
[91] Fang Y, Kuang S, Gao X, Zhang Z. Preparation and characterization of novel nano-encapsulated phase change materials. Energy Conversion and Management 2008; 49: 3704-7.

[92] Khodadadi JM, Hosseinizadeh SF. Nanoparticle-enhanced phase change materials (NEPCM) with great potential for improved thermal energy storage. International Communications in Heat and Mass Transfer 2007; 34: 534-43.

[93] Sari A, Alkan C, Karaipekli A, Uzun O. Microencapsulated n-octacosane as phase change material for thermal energy storage. Solar Energy 2009; 83: 1757-63.

[94] Available fromwww.teappcm.com

[95] Available from www.microteklabs.com

[96] Nath, R. Encapsulation of High Temperature Phase Change Materials for Thermal Energy Storage. Master Thesis, University of South Florida, 2012.

http://scholarcommons.usf.edu/cgi/viewcontent.cgi?article=5376\&context=etd

[97] Nomura, T., Okinaka, N., Akiyama, T. Technology of latent heat storage for high temperature application: a review. ISIJ International, 2010; 50(9): 1229-1239.

[98] Koizumi, H. Time and spatial heat transfer performance around an isothermally heated sphere placed in a uniform, downwardly directed flow (in relation to the enhancement of latent heat storage rate in a spherical capsule).Applied thermal engineering, 2004; 24(17): 2583-2600.

[99] Bilir, L., Ilken, Z. Total solidification time of a liquid phase change material enclosed in cylindrical/spherical containers. Applied thermal engineering, 2005; 25(10): 1488-1502.

[100] Arkar, C., Medved, S. Influence of accuracy of thermal property data of a phase change material on the result of a numerical model of a packed bed latent heat storage with spheres. Thermochimica Acta, 2005; 438(1): 192-201.

[101] Ettouney, H., Alatiqi, I., Al-Sahali, M., Al-Hajirie, K. Heat transfer enhancement in energy storage in spherical capsules filled with paraffin wax and metal beads. Energy conversion and management, 2006; 47(2): 211-228.

[102] Chen, W., Zhu, B., Chen, Z., Li, H., Sun, F. New analysis of contact melting of phase change material around a hot sphere. Heat and Mass Transfer, 2008; 44(3): 281-286. 
[103] Cheng, C. H., Chang, M. H. Shape identification for water-ice interface within the cylindrical capsule in cold storage system by inverse heat transfer method. International journal of refrigeration, 2003; 26(5): 543-550.

[104] Regin, A. F., Solanki, S. C., Saini, J. S. Latent heat thermal energy storage using cylindrical capsule: Numerical and experimental investigations. Renewable energy, 2006; 31(13): 2025-2041.

[105] Kalaiselvam, S., Veerappan, M., Aaron, A. A., Iniyan, S. Experimental and analytical investigation of solidification and melting characteristics of PCMs inside cylindrical encapsulation. International Journal of Thermal Sciences, 2008; 47(7): 858-874.

[106] Hawlader, M. N. A., Uddin, M. S., \& Khin, M. M. (2003). Microencapsulated PCM thermal-energy storage system. Applied energy, 74(1), 195-202.

[107] Liang, C., Lingling, X., Hongbo, S., Zhibin, Z. Microencapsulation of butyl stearate as a phase change material by interfacial polycondensation in a polyurea system. Energy Conversion and Management, 2009; 50(3): 723-729.

108 Fang, Y., Kuang, S., Gao, X., Zhang, Z. Preparation and characterization of novel nano-encapsulated phase change materials. Energy conversion and management, 2008; 49(12): 3704-3707.

[109] Liu, X., Liu, H., Wang, S., Zhang, L., Cheng, H. RETRACTED: Preparation and thermal properties of form stable paraffin phase change material encapsulation. Energy conversion and management, 2006; 47(15): 2515-2522.

[110] Song, Q., Li, Y., Xing, J., Hu, J. Y., Marcus, Y. Thermal stability of composite phase change material microcapsules incorporated with silver nano-particles. Polymer, 2007; 48(11): 3317-3323.

[111]Zhang, H., Wang, X. Fabrication and performances of microencapsulated phase change materials based on n-octadecane core and resorcinol-modified melamine-formaldehyde shell. Colloids and Surfaces A: Physicochemical and Engineering Aspects, 2009; 332(2): 129-138.

[112]Maruoka, N., Akiyama, T. Exergy recovery from steelmaking off-gas by latent heat storage for methanol production. Energy, 2006; 31(10): 1632-1642.

[113] U.S. DOE. 2014: the year of concentrating solar power. 2014.

[114]Agyenim, F., Eames, P., Smyth, M. Heat transfer enhancement in medium temperature thermal energy storage system using a multitube heat transfer array. Renewable Energy 2010; 35(1): 198-207. 
[115] Laing D., Bauer T., Steinmann W. D., Lehmann D. Advanced High Temperature Latent Heat Storage System-Design and Test Results. In Proceedings of the 11th International Conference on Thermal Energy Storage-Effstock. 2009, June, pp.14-17.

[116] Laing D., Bahl C., Bauer T., Lehmann D., Steinmann W. D. Thermal energy storage for direct steam generation. Solar Energy 2011; 85(4): 627-633.

[117]Adinberg, R., Zvegilsky, D., Epstein, M. Heat transfer efficient thermal energy storage for steam generation. Energy Conversion and Management 2010; 51(1): 9-15.

[118]Jegadheeswaran, S., Pohekar, S. D. Performance enhancement in latent heat thermal storage system: a review. Renewable and Sustainable Energy Reviews 2009; 13(9): 2225-2244.

[119]Michels, H., Pitz-Paal, R. Cascaded latent heat storage for parabolic trough solar power plants. Solar Energy, 2007; 81(6): 829-837.

[120]Guo, C., Zhang, W. Numerical simulation and parametric study on new type of high temperature latent heat thermal energy storage system.Energy Conversion and Management 2008; 49(5): 919-927. [121]Seeniraj, R. V., Velraj, R., Narasimhan, N. L. Thermal analysis of a finned-tube LHTS module for a solar dynamic power system. Heat and Mass Transfer 2002; 38(4-5): 409-417.

[122] Li, P.W., Van Lew, J., Chan, C.L., Karaki, W., Stephens, J., O’Brien, J.E. Similarity and generalized analysis of efficiencies of thermal energy storage systems. Renewable Energy 2012; 39(1): $388-402$.

[123]Xu, B., Li, P., Chan, C. L. Energy Storage Start-up Strategies for Concentrated Solar Power Plants With a Dual-Media Thermal Storage System.Journal of Solar Energy Engineering 2015; 137(5): 051002.

[124] Moran, M. J., Shapiro, H. N., Boettner, D. D., Bailey, M. B. 2010, Fundamentals of engineering thermodynamics, 7th Ed., John Wiley \& Sons, New York.

[125]Bjurström, H., Carlsson, B. An exergy analysis of sensible and latent heat storage. Journal of Heat Recovery Systems 1985; 5(3): 233-250.

[126] Adebiyi, G.A., Russell, L.D.. Second law analysis of phase-change thermal energy storage systems. In Proceedings of the ASME heat transfer division 1987; 80: 9-20. Boston, MA.

[127] De Lucia, M., Bejan, A. Thermodynamics of energy-storage by melting due to conduction or natural-convection. J Sol Energy Engineering 1990;112(2):110-116. 
[128] Jegadheeswaran, S., Pohekar, S. D., Kousksou, T. Exergy based performance evaluation of latent heat thermal storage system: a review.Renewable and Sustainable Energy Reviews 2010; 14(9): $2580-2595$.

[129] Keshavarz, A., Mehrabian, M. A., Abolghasemi, M., Mostafavi, A. Availability (exergy) analysis in a thermal energy storage system with the phase change materials arranged in series. Proceedings of the Institution of Mechanical Engineers, Part A: Journal of Power and Energy 2011; 225(1): 44-52.

[130] Li, Y. Q., He, Y. L., Wang, Z. F., Xu, C., Wang, W. Exergy analysis of two phase change materials storage system for solar thermal power with finite-time thermodynamics. Renewable Energy 2012; 39(1): 447-454.

[131] Mahfuz, M. H., Kamyar, A., Afshar, O., Sarraf, M., Anisur, M. R., Kibria, M. A., Metselaar, I. H. S. C. Exergetic analysis of a solar thermal power system with PCM storage. Energy Conversion and Management 2014; 78: 486-492.

[132]Shabgard, H., Bergman, T. L., Faghri, A. Exergy analysis of latent heat thermal energy storage for solar power generation accounting for constraints imposed by long-term operation and the solar day. Energy 2013; 60: 474-484.

[133] Nithyanandam, K., Pitchumani, R. Cost and performance analysis of concentrating solar power systems with integrated latent thermal energy storage. Energy 2014; 64: 793-810.

[134] Kousksou, T., Rhafiki, T. E., Arid, A., Schall, E., Zeraouli, Y. Power, efficiency and irreversibility of latent energy systems. Journal of Thermophysics and Heat Transfer 2008; 22(2): 234-239.

[135]Erek, A., Dincer, I. A new approach to energy and exergy analyses of latent heat storage unit. Heat Transfer Engineering 2009; 30(6): 506-515.

[136] Kousksou, T., Strub, F., Lasvignottes, J.S., Jamil, A., Bedecarrats, J.P. Second law analysis of latent thermal storage for solar system. Sol Energy Mater Sol Cells 2007;91:1275-81.

[137] Bindra, H., Bueno, P., Morris, J. F., Shinnar, R. Thermal analysis and exergy evaluation of packed bed thermal storage systems. Applied Thermal Engineering 2013; 52(2): 255-263.

[138] Xu B., Li P.W., Chan C.L., Tumilowicz E. General volume sizing strategy for thermal storage system using phase change material for concentrated solar thermal power plant. Applied Energy 2015; 140: $256-268$. 
[139] Schumann T. E. Heat transfer: a liquid flowing through a porous prism. Journal of the Franklin Institute 1929; 208(3): 405-416.

[140] Incropera, F. P., DeWitt, D. P. Introduction to Heat Transfer, Fourth Ed. John Wiley and Sons, Inc., 2002.

[141] Nellis, G., Klein, S., Heat Transfer, Cambridge University Press, 2009.

[142] Li P.W., Van Lew J., Karaki W., Chan C.L., Stephens J., O’Brien J.E. Transient heat transfer and energy transport in packed bed thermal storage systems. In book "Developments in Heat Transfer", edited by Marco Aurélio dos Santos Bernardes, ISBN 978-953-307-569-3, September 15. 2011.

[143] Tumilowicz E., Chan C.L., Li P.W.., Xu B. An enthalpy formulation for thermocline with encapsulated PCM thermal storage and benchmark solution using the method of characteristics. International Journal of Heat and Mass Transfer 2014; 79: 362-377.

[144] Van Lew J., Li P.W., Chan C.L., Karaki W., Stephens J. Analysis of heat storage and delivery of a thermocline tank having solid filler material. Journal of Solar Energy Engineering 2011; 133(2): 021003.

[145] Li P.W., Xu B., Han J.X., Yang, Y.P. Verification of a model of thermal storage incorporated with an extended lumped capacitance method for various solid-fluid structural combinations.Solar energy $2014 ; 105: 71-81$.

[146] Xu B., Li P.W., Chan C.L. Extending the validity of lumped capacitance method for large Biot number in thermal storage application. Solar Energy 2012; 86(6): 1709-1724.

[147] Zhang Y., Su Y., Zhu Y., Hu X. A General Model for Analyzing the Thermal Performance of the Heat Charging and Discharging Processes of Latent Heat Thermal Energy Storage Systems. Journal of Solar Energy Engineering 2001; 123(3): 232-236.

[148] Ismail K.A.R., Henriquez J.R. Numerical and experimental study of spherical capsules packed bed latent heat storage system. Applied Thermal Engineering 2002; 22(15): 1705-1716.

[149] Wei J., Kawaguchi Y., Hirano S., Takeuchi H. Study on a PCM heat storage system for rapid heat supply. Applied thermal engineering 2005; 25(17): 2903-2920.

[150] Wu S., Fang G. Dynamic Discharging Characteristics Simulation on Solar Heat Storage System with Spherical Capsules using Paraffin as Heat Storage Material. Renewable Energy 2011; 36 : 1190-95 
[151] Flueckiger S.M., Garimella S.V. Latent heat augmentation of thermocline energy storage for concentrating solar power-A system-level assessment. Applied Energy 2014; 116: 278-287.

[152] Flueckiger S.M., Iverson B.D., Garimella S.V., Pacheco J.E. System-level simulation of a solar power tower plant with thermocline thermal energy storage. Applied Energy 2014; 113: 86-96.

[153] Modi A., Pérez-Segarra C.D. Thermocline thermal storage systems for concentrated solar power plants: One-dimensional numerical model and comparative analysis. Solar Energy 2014; 100: 84-93.

[154] Trp A. An experimental and numerical investigation of heat transfer during technical grade paraffin melting and solidification in a shell-and-tube latent thermal energy storage unit. Solar Energy 2005; 79(6): 648-660.

[155] Marín J. M., Zalba B., Cabeza L. F., Mehling H. Improvement of a thermal energy storage using plates with paraffin-graphite composite. International Journal of Heat and Mass Transfer 2005; 48(12): 2561-2570.

[156] Kousksou T., Bédécarrats J.P., Dumas J.P., Mimet A. Dynamic modelling of the storage of an encapsulated ice tank. Applied Thermal Engineering 2005; 25(10): 1534-1548.

[157] Adine H. A., El Qarnia H. Numerical analysis of the thermal behaviour of a shell-and-tube heat storage unit using phase change materials. Applied Mathematical Modelling 2009; 33(4): 2132-2144.

[158] Wang S., Faghri A., Bergman T.L. A comprehensive numerical model for melting with natural convection. International Journal of Heat and Mass Transfer 2010; 53(9): 1986-2000.

[159] Nithyanandam K., Pitchumani R., Mathur A. Analysis of a latent thermocline storage system with encapsulated phase change materials for concentrating solar power. Applied Energy 2014; 113: 1446-1460.

[160] Lu J., Yu T., Ding J., Yuan Y. Thermal storage performance of molten salt thermocline system with packed phase change bed. Energy Conversion and Management 2015

[161] Zukowski M. Mathematical modeling and numerical simulation of a short term thermal energy storage system using phase change material for heating applications. Energy Conversion and Management 2007; 48(1): 155-165.

[162] MacPhee D., Dincer I. Thermodynamic analysis of freezing and melting processes in a bed of spherical PCM capsules. ASME Journal of Solar Energy Engineering 2009; 131(3): 031017. 
[163] Yang KT. Natural convection in enclosures. In: Kakac S, Shah R, Aung W, editors. Handbook of Single-Phase Convective Heat Transfer. New York: Wiley; 1987.

[164] Jones S.A., Pitz-Paal R., Schwarzboezl P., Blair N., Cable R. TRNSYS modelling of the SEGS VI parabolic trough Solar Electric Generating System, in: Proceedings of ASME International Solar Energy Conference Solar Forum, Washington, DC, April 2001.

[165] Llorente-García I., Álvarez J.L., Blanco D. Performance model for parabolic trough solar thermal power plants with thermal storage: comparison to operating plant data, Solar Energy 2011; 85: 2443-2460.

[166] Greenius, 2011, <http://www.f1.htw-berlin.de/studiengang/ut/downloads/greenius/index.html> [167] SAM, 2011, https://www.nrel.gov/analysis/sam/.

[168] Janjai S., Laksanaboonsong J., Seesaard T. Potential application of concentrating solar power systems for the generation of electricity in Thailand. Applied Energy 2011; 88: 4960-4967.

[169] Bayón R., Rivas E., Rojas E. Study of thermocline tank performance in dynamic processes and stand-by periods with an analytical function, in: SolarPACES2013, Las Vegas, USA, September 2013

[170] Al-Najem N.M. Degradation of a stratified thermocline in a solar storage tank. International journal of energy research 1993; 18: 183-191.

[171] Bayón R., Rojas E. Analytical function describing the behaviour of a thermocline storage tank: A requirement for annual simulations of solar thermal power plants. International Journal of Heat and Mass Transfer 2014; 68: 641-648.

[172] Biencinto M., Bayón R., Rojas E., González L. Simulation and assessment of operation strategies for solar thermal power plants with a thermocline storage tank. Solar Energy 2014; 103: 456-472.

[173] Zanganeh G., Commerford M., Haselbacher A., Pedretti A., Steinfeld A. Stabilization of the outflow temperature of a packed-bed thermal energy storage by combining rocks with phase change materials. Applied Thermal Engineering 2014; 70(1): 316-320.

[174] Kenisarin M. M. High-temperature phase change materials for thermal energy storage. Renewable and Sustainable Energy Reviews 2010; 14(3): 955-970.

http://blueribbonchem.en.alibaba.com/product/2006714384-222194830/NaF_Sodium fluoride industr ע_grade CAS_No $7681 \_494$.html 
[176] http://www.alibaba.com/product-detail/price-for-sodium-nitrate-nano3_60069588753.html

[177]

http://www.lookchem.com/product_Potassium-fluoride-7789-23-3-Industrial-Grade/12711587.html

[ 178 ]http://www.alibaba.com/product-detail/potassium-nitrate-fertilizer-industry-grade-price_6020490

7101.html?s=p

[179] http://www.alibaba.com/product-detail/Industry-Grade-98-Magnesium-Fluoride_826857424.html $\underline{? \mathrm{~s}=\mathrm{p}}$

[180] http://www.alibaba.com/product-detail/Calcium-Nitrate-Ca-NO3-2_366523581.html?s=p

[181]http://sjzbcchem.en.alibaba.com/product/617008779-213404332/Calcium_Fluoride_Industry_Gra $\underline{\text { de.html }}$

[ 182 ] http://www.alibaba.com/product-detail/99-rock-salt-industry-grade-sodium_1936541165.html?s= p

[183]http://www.alibaba.com/product-detail/Industry-grade-low-price-Aluminum-Fluoride 939488531 $\underline{. h t m l}$

[184] http://www.alibaba.com/product-detail/potassium-chloride-industrial-grade 906506233.html?s=p

[185]http://www.alibaba.com/product-detail/China-Manufacturer-Industrial-Salt-Soda-Ash_196751807 $\underline{1 . h t m l ? s=p}$

[186]http://www.alibaba.com/product-detail/mgcl2-magnesium-chloride-industrial-grade_1436303095. $\underline{h t m l ? s=p}$

[ 187 ]http://www.alibaba.com/product-detail/99-Industrial-Grade-Lithium-Carbonate-li2co3_60081001 $\underline{046 . h t m l ? s=p}$

[188] http://crownchampion.en.alibaba.com/product/60025626814-215588143/Industry_Grade_BaCl2 Barium_Chloride_Dihydrate_Price.html

[ 189 ] http://fono-chem.en.alibaba.com/product/1954800139-801257893/potassium_carbonate k2co3_I $\underline{\text { ndustrial_Grade.html }}$

[190] ]http://www.alibaba.com/product-detail/Factory-direct-Calcium-Chloride-industrial-grade 199332 3891.html?s=p

[ 191 ] http://www.alibaba.com/product-detail/Sodium-carbonate-Na2CO3-soda-ash-99 1936415102.ht $\underline{\mathrm{ml} ? \mathrm{~s}=\mathrm{p}}$ 
[192] http://www.alibaba.com/product-detail/Strontium-Chloride-99-5-_489589382.html

[193] http://www.alibaba.com/product-detail/Potassium-Hydroxide_1011079786.html?s=p

[194] http://www.alibaba.com/product-detail/China-Origin-Industry-Grade-Zinc-Chloride_1044540975. $\underline{h t m l ? s=p}$

[195] Glatzmaier G. Developing a cost Model and methodology to estimate capital costs for thermal energy storage. National Renewable Energy Laboratory; 2011. pp. 1-17. NREL/TP-550053066.

[196] Kelly B, Kearney D. Thermal storage commercial plant design for a 2-tank indirect molten salt system. National Renewable Energy Laboratory; 2006. pp. 1-32. NREL/SR-550040166.

[197] Mathur A. Personal communication: Terrafore, Inc.; 2012.

[198] Pacheco JE, Showalter SK, Kolb WJ. Development of a molten-salt thermocline thermal storage system for parabolic trough plants. ASME Journal of Solar Energy Engineering 2002; 124(2): 153-9 [199] EPRI, 2010. Solar Thermocline Storage Systems: Preliminary Design Study. <http://et.epri.com/publicdocuments.html-1019581>

[200] Strasser M. N., Selvam R. P. A cost and performance comparison of packed bed and structured thermocline thermal energy storage systems. Solar Energy 2014; 108: 390-402.

[201] Xu B., Li P.W, Chan C.L. Volume Sizing for Thermal Storage with Phase Change Material for Concentrated Solar Power Plant. In Proceedings of ASME 2014 8th International Conference on Energy Sustainability. 2014, June, Boston, MA.

[202] http://www.nrel.gov/analysis/tech_lcoe.html 